\title{
Reactivity of neodymium carriers in deep sea sediments: implications for boundary exchange and paleoceanography
}

\author{
David J. Wilson *, \\ Alexander M. Piotrowski, \\ Albert Galy, \\ Josephine A. Clegg \\ Godwin Laboratory for Palaeoclimate Research, Department of Earth Sciences, \\ University of Cambridge, Cambridge, CB2 3EQ, United Kingdom \\ * Corresponding Author: \\ Now at Department of Earth Science and Engineering, Imperial College London, \\ London, SW7 2AZ, United Kingdom \\ Email: david.wilson1@imperial.ac.uk \\ Office tel: +442075946463
}

Revised manuscript for Geochimica et. Cosmochimica Acta

$26^{\text {th }}$ January 2013 


\begin{abstract}
The dissolved neodymium $(\mathrm{Nd})$ isotopic distribution in the deep oceans is determined by continental weathering inputs, water mass advection, and boundary exchange between particulate and dissolved fractions. Reconstructions of past $\mathrm{Nd}$ isotopic variability may therefore provide evidence on temporal changes in continental weathering inputs and/or ocean circulation patterns over a range of timescales. However, such an approach is limited by uncertainty in the mechanisms and importance of the boundary exchange process, and the challenge in reliably recovering past seawater $\mathrm{Nd}$ isotopic composition $\left(\varepsilon_{\mathrm{Nd}}\right)$ from deep sea sediments. This study addresses these questions by investigating the processes involved in particulate-solution interactions and their impact on $\mathrm{Nd}$ isotopes. A better understanding of boundary exchange also has wider implications for the oceanic cycling and budgets of other particle-reactive elements.

Sequential acid-reductive leaching experiments at $\mathrm{pH} \sim 2-5$ on deep sea sediments from the western Indian Ocean enable us to investigate natural boundary exchange processes over a timescale appropriate to laboratory experiments. We provide evidence that both the dissolution of solid phases and exchange processes influence the $\varepsilon_{\mathrm{Nd}}$ of leachates, which suggests that both processes may contribute to boundary exchange. We use major element and rare earth element data to investigate the pools of $\mathrm{Nd}$ that are accessed and demonstrate that sediment leachate $\varepsilon_{\mathrm{Nd}}$ values cannot always be explained by admixture between an authigenic component and the bulk detrital component. For example, in core WIND 24B, acid-reductive leaching generates $\varepsilon_{\mathrm{Nd}}$ values between -11 and -6 as a function of solution/solid ratios and leaching times, whereas the authigenic components have $\varepsilon_{\mathrm{Nd}} \approx-11$ and the bulk detrital component has $\varepsilon_{\mathrm{Nd}} \approx-15$. We infer that leaching in the Mascarene Basin accesses authigenic components and a minor radiogenic volcanic component that is more reactive than Madagascan-derived clays. The preferential mobilisation of such a minor component demonstrates that the $\mathrm{Nd}$ released by boundary exchange could often have a significantly different $\varepsilon_{\mathrm{Nd}}$ composition than the bulk detrital sediment.

These experiments further demonstrate certain limitations on the use of acid-reductive leaching to extract the $\varepsilon_{\mathrm{Nd}}$ composition of the authigenic fraction of bulk deep sea sediments. For example, the detrital component may contain a reactive fraction which is also acidextractible, while the incongruent nature of this dissolution suggests that it is often inappropriate to use the bulk detrital sediment elemental chemistry and/or $\varepsilon_{\mathrm{Nd}}$ composition when assessing possible detrital contamination of leachates. Based on the highly systematic controls observed, and evidence from REE patterns on the phases extracted, we suggest two approaches that lead to the most reliable extraction of the authigenic $\varepsilon_{\mathrm{Nd}}$ component and good agreement with foraminiferal-based approaches; either (i) leaching of sediments without a prior decarbonation step, or (ii) the use of short leaching times and low solution/solid ratios throughout.
\end{abstract}




\section{INTRODUCTION}

The neodymium (Nd) isotopic composition of seawater is spatially heterogeneous, reflecting isotopically distinct weathering inputs from the surrounding continents (Goldstein and Jacobsen, 1987; Peucker-Ehrenbrink et al., 2010). Nd isotopes are also described as a quasi-conservative tracer for inter- and intra-basin water mass mixing (Piepgras et al., 1979; Goldstein and Hemming, 2003) because the oceanic residence time of Nd ( 200-1000 yrs; Tachikawa et al., 1999; Tachikawa et al., 2003; Siddall et al., 2008; Rempfer et al., 2011) is shorter than the mixing time of the deep ocean ( 1500 yrs; Broecker and Peng, 1982). Therefore, reconstructions of past seawater $\mathrm{Nd}$ isotopic compositions $\left(\varepsilon_{\mathrm{Nd}}\right)$ can potentially provide evidence on temporal changes in continental weathering inputs and ocean circulation patterns (O'Nions et al., 1998; Frank, 2002; Goldstein and Hemming, 2003). However, our understanding of the controls on the dissolved $\varepsilon_{\mathrm{Nd}}$ distribution in the deep ocean is incomplete, leading to a degree of uncertainty in such interpretations. Weathering and erosion of the continents represent the ultimate source of dissolved Nd to the oceans (PeuckerEhrenbrink et al., 2010), but the relative importance of dissolved versus particulate inputs remains uncertain (Oelkers et al., 2011). In particular, there is emerging evidence that exchange between particulate and dissolved fractions, particularly along ocean margins, may exert an important control on the deep ocean $\mathrm{Nd}$ budget and $\varepsilon_{\mathrm{Nd}}$ distribution; a process (or multitude of processes) that has been termed 'boundary exchange' (Jeandel et al., 1995; Tachikawa et al., 1999; Lacan and Jeandel, 2001; Lacan and Jeandel, 2005). Understanding boundary exchange may be important for understanding not only the oceanic cycling of $\mathrm{Nd}$ but also that of a wide range of other elements (Jeandel et al., 2011; Oelkers et al., 2011).

The observational evidence for boundary exchange is mostly from modern seawater studies which demonstrate changes in $\varepsilon_{\mathrm{Nd}}$ composition along deep water flow paths in some locations (e.g. Jeandel et al., 1998; Lacan and Jeandel, 2001; Lacan and Jeandel, 2005; Amakawa et al., 2009; Carter et al., 2012; Grasse et al., 2012), but these do not generally provide evidence on the mechanisms involved. Boundary exchange has also been investigated in global ocean modelling studies (Arsouze et al., 2007; Jones et al., 2008; Arsouze et al., 2009; Arsouze et al., 2010; Rempfer et al., 2011) which serve to illustrate its potential importance. However, discrepancies between modelling studies also demonstrate that the mechanism for boundary exchange is poorly understood - for example, it may involve some combination of release, removal and exchange of $\mathrm{Nd}$ between seawater and ocean margin sediments; it is not clear how these processes are spatially distributed; and it is not known which particular sediment phases are involved. Boundary exchange therefore represents a major unknown in our understanding of the present day oceanic Nd cycling and a significant challenge for the paleoceanographic interpretation of past changes in seawater $\varepsilon_{\mathrm{Nd}}$ (e.g. Wilson et al., 2012).

One fundamental question that must be addressed pertaining to boundary exchange is whether the bulk $\varepsilon_{\mathrm{Nd}}$ composition of ocean margin detrital sediments can be considered representative of the composition that contributes to boundary exchange. This assumption has formed the basis for studies to date (e.g. Lacan and Jeandel, 2005; Arsouze et al., 2009) but 
remains largely unproven. A second key question is whether boundary exchange represents a true exchange process, or whether it records the dissolution of particulate phases which, if spatially coupled to removal processes, may provide the impression of an exchange process at a regional scale. To date, few experimental studies have addressed these questions or investigated boundary exchange more generally. A boundary exchange process occurred in batch reactor experiments on various riverine sediments but not on the one estuarine sediment sample studied to date (Jones et al., 2012). Since estuarine sediments are likely to represent more closely the material that is transferred to the oceans, we do not yet have experimental evidence to support the observational evidence for boundary exchange in the deep ocean (Lacan and Jeandel, 2005).

Paleoceanographic studies have attempted to reconstruct past seawater $\varepsilon_{\mathrm{Nd}}$ compositions using authigenic phases such as ferromanganese crusts/nodules (e.g. O'Nions et al., 1978; Piepgras et al., 1979; Frank, 2002), foraminifera (e.g. Palmer and Elderfield, 1985; Vance et al., 2004; Klevenz et al., 2008; Roberts et al., 2010), fish teeth (e.g. Staudigel et al., 1985; Martin and Haley, 2000) and sequential acid-reductive leaching of bulk sediment (e.g. Chester and Hughes, 1967; Rutberg et al., 2000; Bayon et al., 2002; Piotrowski et al., 2004; Gutjahr et al., 2007; Pahnke et al., 2008; Martin et al., 2010). Sediment leaching has the potential to provide the best spatial coverage and temporal resolution, but does not appear to provide a reliable reconstruction of seawater $\varepsilon_{\mathrm{Nd}}$ in all locations, and it has been suggested that leachates may be contaminated by the laboratory leaching of a detrital volcanic component (Vance et al., 2004; Roberts et al., 2010; Elmore et al., 2011). A lack of understanding of the sediment leaching process, and of the phases preserving the authigenic signal, limits the reliability and utility of this approach at present, but it may also open the door towards a better understanding of the lability of $\mathrm{Nd}$ in deep sea sediments.

In this study we investigate the reactivity of the Nd-carrying phases within bulk deep sea sediments using sequential acid-reductive leaching experiments. We take advantage of the favourable reaction kinetics at low $\mathrm{pH}$ and room temperature (Casey and Ludwig, 1995; Sverdrup and Warfvinge, 1995) to investigate possible boundary exchange processes over a timescale appropriate to laboratory experiments, and interpret our data in the context of theories on the kinetics of exchange and mineral dissolution (e.g. Luce et al., 1972). Specifically, we investigate the sensitivity of leachate $\varepsilon_{\mathrm{Nd}}$ values, REE patterns and major elemental chemistry to variables in the acid-reductive leaching process (i.e. leaching time, volume and sample size). This provides new insight into (i) the mechanisms and controls on the boundary exchange process appropriate to deep sea settings; and (ii) the reliable recovery of the $\varepsilon_{\mathrm{Nd}}$ composition of the authigenic component of deep sea sediments by reductive leaching.

\section{METHODS}

\subsection{Sampling}


The sediment samples are from the suite of WIND cores recovered from the deep western Indian Ocean on the R.R.S. Charles Darwin Cruise 129 (McCave, 2001). We have previously presented $\varepsilon_{\mathrm{Nd}}$ data on sedimentary foraminifera, bulk sediment acid-reductive leachates and detrital sediments from Holocene age box coretop samples $(0-2 \mathrm{~cm}$ core depth) in 8 WIND cores from the Madagascar and Mascarene Basins (Wilson et al., 2012) and showed that there are significant differences in $\varepsilon_{\mathrm{Nd}}$ between the authigenic and detrital fractions. In this study, a subset of three cores from the Mascarene Basin (WIND 24B, 28B and 32B; Fig. 1) was selected for leaching experiments in order to represent a wide range of carbonate contents (25\% to $80 \%$ ) and clay mineralogy (Table 1). One further core from the Mozambique Basin (WIND 1B) was included to extend the geographical coverage to a basin with different detrital sediment inputs (Kolla et al., 1976). All the leaching experiments were carried out on coretop samples (i.e. 0-2 cm core depth) of Holocene age.

\subsection{Sediment leaching experiments}

Sequential selective chemical leaching provides a means to investigate the different pools of elements present within a sediment sample (Tessier et al., 1979). The caveat is that these fractions are operationally-defined and complete separation may not always be possible (e.g. Rendell and Batley, 1980; Tipping et al., 1985; Kheboian and Bauer, 1987; Sholkovitz, 1989). Our experiments follow a sequential selective chemical leaching procedure that has been developed by the $\mathrm{Nd}$ isotope community for making paleoceanographic reconstructions (Chester and Hughes, 1967; Rutberg et al., 2000; Bayon et al., 2002; Piotrowski et al., 2004; Tachikawa et al., 2004; Gutjahr et al., 2007; Martin et al., 2010). In these studies, sediment samples are leached in buffered acetic acid solution (which is considered to remove carbonate) and subsequently leached in an acid-reductive solution of hydroxylamine hydrochloride in acetic acid (in order to recover an authigenic component that is assumed to be dominated by ferromanganese oxide coatings on detrital and biogenic grains), while the residue after such extractions is considered to correspond to the detrital component. In detail, the procedure in our experiments was as follows:

a) Samples were leached multiple times in $30 \mathrm{~mL} 0.44 \mathrm{M}$ acetic acid solution (buffered to $\mathrm{pH} 5$ by $2.46 \mathrm{~g}$ sodium acetate) in $50 \mathrm{~mL}$ centrifuge tubes. This was carried out on a vertical rotating wheel $(24 \mathrm{~cm}$ in diameter, $30 \mathrm{rpm})$ at room temperature over a period of days to weeks. After each leach, the samples were centrifuged at $3500 \mathrm{rpm}$, the acetic acid was poured to waste and replaced with fresh acetic acid, and the samples were vortex mixed at $3000 \mathrm{rpm}$ on a Vortex Genie 2 before being returned to the wheel.

b) Samples were water washed at least twice with de-ionised water, with vortex mixing as above and centrifuging at $4500 \mathrm{rpm}$ each time.

c) Samples were leached (for typically 1 hour) in a pH 2 acid-reductive solution of 0.02 $\mathrm{M}$ hydroxylamine hydrochloride $(\mathrm{HH})$ in $4.4 \mathrm{M}$ acetic acid (typically $30 \mathrm{~mL}$ ), in 50 $\mathrm{mL}$ centrifuge tubes on a rotating wheel at room temperature. This $\mathrm{HH}$ leachate was 
centrifuged at $5000 \mathrm{rpm}$ and decanted, three times in sequence, to prevent the transfer of detrital particles.

d) Samples were dried down and a $5 \%$ aliquot for analysis of elemental concentrations was taken by re-dissolving in de-ionised water before the remainder of the sample was chemically separated for $\mathrm{Nd}$ isotope analysis.

Applying this procedure, a series of leaching experiments (i-v) was carried out (Table 2). An overview is presented below and the details are reported in Table 3.

\subsubsection{Experiment (i): Effect of sample size (WIND 1B, 24B, 28B, 32B)}

The bulk sediment was sub-sampled to provide larger samples $(\sim 12-14 \mathrm{~g}$ prior to decarbonation, wet weights) and smaller samples ( 4-5 g prior to decarbonation, wet weights) for WIND 1B, 24B, 28B and 32B. All samples were leached in $30 \mathrm{~mL} 0.44 \mathrm{M}$ buffered acetic acid, either 15 times over 24 days (for WIND 24B and WIND 28B) or 15 times over 48 days (for WIND 1B and WIND 32B), and then leached (after water washing) for 1 hour in $30 \mathrm{~mL} 0.02 \mathrm{M} \mathrm{HH}$.

\subsubsection{Experiment (ii): Effect of acetic acid leaching volume (WIND 24B)}

Multiple samples of the same size $(\sim 4.5 \mathrm{~g})$ were repeatedly leached in $30 \mathrm{~mL} 0.44 \mathrm{M}$ acetic acid solution different numbers of times, up to a total of 10 leaches over 27 days (Table

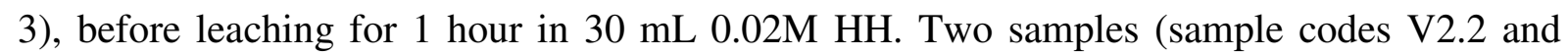
V2.7; Table 3) were leached twice in acetic acid but using different leaching times for the second acetic acid leach, leading to a total of either 2 days or 7 days of leaching, respectively. (The first number in sample codes refers to the number of acetic acid leaches and the second number to the total number of days of acetic acid leaching.) A number of complete procedural replicates were also analysed, including some that had undergone additional vortex mixing (Table 3).

\subsubsection{Experiment (iii): Effect of HH leaching time for non-decarbonated sediments (WIND} 24B)

Samples of $\sim 4.5 \mathrm{~g}$ were leached in $30 \mathrm{~mL} 0.02 \mathrm{M} \mathrm{HH}$ for 30, 60, 120, 240 and 480 minutes, without any prior acetic acid leaching (i.e. only water washing).

\subsubsection{Experiment (iv): Effect of HH leaching time for decarbonated sediments (WIND 24B)}

Samples of $\sim 4.5 \mathrm{~g}$ were leached in $30 \mathrm{~mL} 0.02 \mathrm{M} \mathrm{HH}$ for 30, 60, 90, 230 and 325 minutes, after being acetic acid leached 10 times as in experiment (ii). 
Samples of $\sim 4.5 \mathrm{~g}$ were leached in $10 \mathrm{~mL}, 30 \mathrm{~mL}$ or $50 \mathrm{~mL} 0.02 \mathrm{M} \mathrm{HH}$ for 60 minutes, after acetic acid leaching 14 times over 31 days. Whereas all the other experiments used bulk sediment, in this case the fine fraction $(<63 \mu \mathrm{m})$ was used instead.

\subsection{Chemical purification and mass spectrometry}

\subsubsection{Nd isotopes}

The rare earth element fraction was separated using Eichrom TRUspec ${ }^{\mathrm{TM}}$ resin (100$150 \mu \mathrm{m}$ mesh) in $100 \mu \mathrm{l}$ Teflon columns, and the Nd fraction was isolated using Eichrom LNspec $^{\mathrm{TM}}$ resin (50-100 $\mu \mathrm{m}$ mesh) on volumetrically calibrated Teflon columns. The $\mathrm{Nd}$ isotopic composition was analysed on the $\mathrm{Nu}$ Plasma multi-collector inductively coupled plasma mass spectrometer (MC-ICP-MS) in the Department of Earth Sciences at the University of Cambridge, using an exponential mass fractionation correction (to ${ }^{146} \mathrm{Nd} /{ }^{144} \mathrm{Nd}$ $=0.7219$ ), standard-sample bracketing with concentration-matched JNdi-1 neodymium isotope standard (Tanaka et al., 2000) and expressed as $\varepsilon_{\mathrm{Nd}}$. Typical external reproducibility for $25 \mathrm{ng}$ of $\mathrm{Nd}$ is $\sim 0.3 \varepsilon_{\mathrm{Nd}}$ units. Data were collected in a number of analytical sessions and measurement errors are taken from the within-session standard deviation $(2 \sigma)$ on concentration-matched JNdi-1 standards. For samples analysed in duplicate, the reported values are the mean, weighted according to the variance, and the $2 \sigma$ standard error. All $\mathrm{Nd}$ isotope data are reported in Table 3.

\subsubsection{Iron, Manganese, Aluminium, Calcium and REE's}

Elemental concentrations of selected elements ( $\mathrm{Fe}, \mathrm{Mn}, \mathrm{Al}, \mathrm{Ca}$ and REE's) were measured on a PerkinElmer SCIEX Elan DRC II Quadrupole inductively-coupled plasma mass spectrometer (ICP-MS) in the Department of Earth Sciences at the University of Cambridge. After blank subtraction and corrections for the internal standard and oxide interferences on the middle and heavy REE's, signal intensities were converted to concentrations using a calibration based on USGS rock standards (BIR-1, AGV-1, BHVO-2 and BCR-2). The accuracy was assessed by running USGS rock standard BCR-2 as an unknown sample, giving results which match the absolute literature values to better than $10 \%$ for all reported elements and better than $5 \%$ for REE's.

Elemental data are reported as the (Mass of element in leachate)/(Bulk mass of sediment leached) e.g. ng Nd/gram sediment (Table 4), where the bulk masses of sediment are based on wet weights of the sediment residue after $\mathrm{HH}$ leaching. Any absolute error introduced by this normalisation to wet weights (for example, dependent on properties of the sediment such as porosity) is likely to be greater when comparing samples from different cores than when comparing samples from the same core, and in any case it does not affect elemental ratios or REE patterns. Data for detrital samples are recorded as the (Mass of 
element in dissolution)/(Mass of sediment digested), with the weights in this case representing dry weights.

Shale-normalised REE data are plotted using the values of Post Archaean Average Shale (PAAS) from McLennan (1989), with the exception of Tm for which $0.44 \mathrm{ppm}$ is used instead of $0.405 \mathrm{ppm}$, since a comparison to other shale composites suggests this is more representative of its behaviour relative to $\mathrm{Er}$ and $\mathrm{Yb}$. The Tm value used here is transferred from the $\mathrm{Tm} /(\mathrm{Er}+\mathrm{Yb})$ in the North American Shale Composite (NASC), although this choice has no bearing on any of the interpretation presented in this study. Where the shape of the REE patterns is quantified (Table 4), the following parameters are used (all PAAS normalised values, after Martin et al., 2010): LREE $=\mathrm{La}+\mathrm{Pr}+\mathrm{Nd}$, MREE $=\mathrm{Gd}+\mathrm{Tb}+\mathrm{Dy}$, HREE = $\mathrm{Tm}+\mathrm{Yb}+\mathrm{Lu}, \mathrm{MREE} / \mathrm{MREE} *=2 \times \mathrm{MREE} /(\mathrm{LREE}+\mathrm{HREE}), \mathrm{Ce} / \mathrm{Ce} *=2 \times \mathrm{Ce} /(\mathrm{La}+\mathrm{Pr})$.

\section{RESULTS}

\subsection{Experiment (i): Effect of sample size (WIND 1B, 24B, 28B, 32B)}

Experiment (i) investigates the effect of sample size (with constant leaching volumes and times) on the sediment leaching in four different sediment cores. For samples from Mascarene Basin cores WIND 24B, 28B and 32B, HH leaching of different sample sizes leads to different $\varepsilon_{\mathrm{Nd}}$ values being obtained (Fig. 2). The 12-14 g samples record less radiogenic $\varepsilon_{\mathrm{Nd}}$ and 4-5 g samples record more radiogenic $\varepsilon_{\mathrm{Nd}}$ in each case, with differences of $\sim 4 \varepsilon_{\mathrm{Nd}}$ units for WIND 24B, $3 \varepsilon_{\mathrm{Nd}}$ units for WIND 28B and $\sim 2 \varepsilon_{\mathrm{Nd}}$ units for WIND 32B. There is good reproducibility for total procedural replicates for a given sample size (Table 3 , Fig. 2), confirming that the $\varepsilon_{\mathrm{Nd}}$ differences are not due to sedimentological heterogeneity within the core. The compositions of the 12-14 g leachates agree (within error) with the compositions of isolated authigenic phases (sedimentary foraminifera) in each core (Fig. 2), whereas the more radiogenic compositions of the 4-5 g leachates fall outside the range of compositions that could be produced by mixing between the authigenic and bulk detrital components (Fig. 2). In the Mozambique Basin core WIND 1B, leachate $\varepsilon_{\mathrm{Nd}}$ values are independent of sample size and in good agreement with the authigenic composition inferred from foraminifera (Fig. 2).

The 12-14 g leachates from experiment (i) have REE patterns characterised by negative Ce anomalies and weak MREE enrichment in all cores (Fig. 3), while HREE/LREE ratios differ between cores (ranging from LREE-enriched for WIND 24B to HREE-enriched for WIND 32B). In contrast, the 4-5 g leachates have positive $\mathrm{Ce}$ anomalies and weaker MREE enrichment, or in the case of WIND 32B a MREE-depleted pattern (Fig. 3). We therefore emphasise that there is some correspondence between differences in $\varepsilon_{\mathrm{Nd}}$ and differences in REE patterns as a function of sample size, but also that there are differences in this behaviour between cores. For example, in WIND 1B sample size affects REE patterns but not $\varepsilon_{\mathrm{Nd}}$ compositions (Fig. 3a,b). We also note that there is a large concentration difference 
between 12-14 $\mathrm{g}$ and 4-5 g leachates in WIND 32B (Fig. 3g), whereas this is not the case in the other cores (Fig. 3a,c,e).

\subsection{Experiment (ii): Effect of acetic acid leaching volume (WIND 24B)}

The amount of acetic acid leaching employed before the $\mathrm{HH}$ leaching affects the elemental chemistry of HH leachates from core WIND 24B (Fig. 4a). The Ca concentrations change over several orders of magnitude between one and five acetic acid leaches, but after five acetic acid leaches (i.e. a total volume of $140 \mathrm{~mL}$ ) do not change further (Fig. 4a), indicating that decarbonation is complete at this point. On this basis the leaching is divided into stage 1 (carbonate removal) and stage 2 (continued acetic acid leaching after decarbonation). $\mathrm{Nd}$ concentrations show a similar but less extreme behaviour to $\mathrm{Ca}$, with 20 times less $\mathrm{Nd}$ recovered after five leaches than after one leach (Fig. 4a), indicating removal of $\mathrm{Nd}$ during stage 1. For two samples subjected to the same number of acetic acid leaches, but one of these for a varying length of time (V2.2 and V2.7; Fig. 4a), the $\mathrm{Ca}$ and $\mathrm{Nd}$ concentrations are similar, suggesting that saturation of the acetic acid solution with respect to dissolved ions is reached within less than one day and that the cumulative acetic acid leaching volume provides the control on element removal during stage 1. Mn also decreases somewhat during stage 1 , but to a lesser degree than $\mathrm{Ca}$ and $\mathrm{Nd}$, while there is little change in $\mathrm{Fe}$ and $\mathrm{Al}$ (Fig. 4a). During stage 2, the extracted concentrations of all these elements in the $\mathrm{HH}$ leachates are essentially unchanging (Fig. 4a).

In contrast to the concentration data, the $\varepsilon_{\mathrm{Nd}}$ composition of the leachates displays an approximately linear trend (Fig. $4 \mathrm{~b}$ ), with a range comparable to the variability observed for WIND 24B in experiment (i) (Fig. 2). We therefore note that the leached $\varepsilon_{\mathrm{Nd}}$ composition changes both during stage 1 (before decarbonation is complete) and during stage 2 (with continued acetic acid leaching). Whereas the $\mathrm{Nd}$ concentrations respond to the cumulative acetic acid leaching volume during stage 1, comparison of samples V2.2 and V2.7 (Fig. 4b) indicates that the acetic acid leaching time exerts an additional control on the $\varepsilon_{\mathrm{Nd}}$ compositions. Comparison with the compositions of isolated authigenic and detrital phases in WIND 24B (Fig. 4b) reveals that HH leachates with only a small amount of decarbonation have an $\varepsilon_{\mathrm{Nd}}$ composition comparable to that of the authigenic phases, while the shift in $\mathrm{HH}$ leachate $\varepsilon_{\mathrm{Nd}}$ values away from this composition towards a more radiogenic composition cannot correspond to admixture with the bulk detrital component of the sediment.

During stage 1, the REE patterns from the earliest stages of leaching (V1.1, V2.2, V2.7; Fig. 5) are similar to each other, and also similar to the REE patterns of uncleaned sedimentary foraminifera from this core (Fig. 5b): both show a MREE bulge, no significant HREE/LREE enrichment and a negative Ce anomaly. Later in stage 1, after three or four acetic acid leaches (V3.3, V4.7), the REE concentrations are around an order of magnitude lower (Fig. 5a) and the REE patterns are LREE-enriched with a smaller Ce anomaly (Fig. 5b). In stage 2, the REE pattern is LREE-enriched with a weak MREE bulge and a positive Ce anomaly, and the only difference between samples is an increasing $\mathrm{Ce}$ anomaly with increasing acetic acid leaching (Fig. 5b). 


\subsection{Experiment (iii): Effect of $\mathrm{HH}$ leaching time for non-decarbonated sediments (WIND 24B)}

For non-decarbonated samples from WIND 24B, the HH leachates of experiment (iii) have an elemental composition (Fig. 6a,b) that is broadly comparable to that observed in stage 1 of experiment (ii) (Fig. 4a), but which also varies with the $\mathrm{HH}$ leaching time. With increasing $\mathrm{HH}$ leaching time from 30 to 480 minutes, there is no increase in $\mathrm{Ca}$ or $\mathrm{Mn}$ concentrations, but there is a small increase in $\mathrm{Nd}$ and there are significant increases in $\mathrm{Fe}$ and $\mathrm{Al}$ (Fig. 6a,b), with the latter three elements forming linear relationships with the square root of time (Fig. 6a,b). Crossplots reveal a close linear relationship between $\mathrm{Nd}$ and both $\mathrm{Fe}$ and $\mathrm{Al}$, but also a significant $\mathrm{y}$-intercept for $\mathrm{Nd}$ where $\mathrm{Fe}=0$ or $\mathrm{Al}=0$ (Fig. 7a,b). The $\mathrm{HH}$ leaching time does not affect the $\varepsilon_{\mathrm{Nd}}$ values of the leachates (Fig. 6c), which fit at the unradiogenic end of the array from experiment (ii) (i.e. $\varepsilon_{\mathrm{Nd}}=-11.0$ to -11.5 ; Fig. $4 \mathrm{~b}$ ) and are in agreement with the $\varepsilon_{\mathrm{Nd}}$ composition of uncleaned foraminifera (Fig. 6c).

The REE patterns from experiment (iii) (Fig. 8a-c) are comparable to those of samples from stage 1 of experiment (ii) (Fig. 5b). With increasing $\mathrm{HH}$ leaching time there is a small increase in REE concentrations (Fig. 8a), which is also associated with a change in the Ce anomaly from negative to flat and a reduction in the MREE enrichment (Fig. 8b). The REE pattern in the 30 minute leach is consistent with the REE pattern of uncleaned foraminifera, whereas the REE's released over the subsequent leaching (450 minutes duration) have a pattern (HREE-enriched, MREE-enriched, positive Ce anomaly) that matches the REE pattern typical of marine ferromanganese nodules (Kuhn et al., 1998) (Fig. 8c).

\subsection{Experiment (iv): Effect of HH leaching time for decarbonated sediments (WIND} 24B)

For decarbonated samples from WIND 24B, the HH leachates of experiment (iv) have an elemental composition (Fig. 6d,e) that is broadly comparable to that observed in stage 2 of experiment (ii) (Fig. 4a). As a function of time, Mn concentrations hardly change, while there are moderate increases in $\mathrm{Fe}$ and $\mathrm{Al}$ and large increases in $\mathrm{Nd}$ and $\mathrm{Ca}$ (Fig. 6d,e). As in experiment (iii), the relationship of these elements with the square root of time is approximately linear. Crossplots also demonstrate the approximately linear relationships between $\mathrm{Nd}$ concentrations and $\mathrm{Fe}$ and $\mathrm{Al}$ concentrations in experiment (iv) (Fig. 7c,d), and these correlations approximately intersect the origin in Fe-Nd and Al-Nd crossplots, unlike in experiment (iii) (Fig. 7a,b). In experiment (iv) there is also resolvable variability in $\varepsilon_{\mathrm{Nd}}$ as a function of the $\mathrm{HH}$ leaching time (Fig. 6f), which was not observed in experiment (iii) (Fig. $6 c$ ), with $\varepsilon_{\mathrm{Nd}}$ compositions becoming increasingly radiogenic with a longer leaching time (Fig. 6f).

The REE patterns in experiment (iv) (Fig. 8d-f) are comparable to those of samples from stage 2 of experiment (ii) (Fig. 5b). With increasing $\mathrm{HH}$ leaching time there is a large increase in REE concentrations (Fig. 8d) and the additional REE's released over this longer 
leaching period have the same REE pattern to the REE's initially released, with the exception of a larger Ce anomaly (Fig. 8f). This pattern is LREE-enriched and does not match the composition of ferromanganese nodules (cf. experiment (iii); Fig. 8c), but there is instead quite good agreement with the REE patterns of the detrital sediment residue in this core (Fig. 8f). Nevertheless, we again emphasise that these leachates have significantly different $\varepsilon_{\mathrm{Nd}}$ compositions from the detrital sediments (Fig. 2).

\subsection{Experiment (v): Effect of HH leaching volume for decarbonated sediments (WIND} 24B)

For decarbonated samples from WIND 24B, the amount of $\mathrm{Fe}, \mathrm{Mn}$ and $\mathrm{Ca}$ extracted by $\mathrm{HH}$ leaching is essentially independent of leaching volume, whereas for $\mathrm{Al}$ and $\mathrm{Nd}$ there is a strong control of the leaching volume and a close to linear relationship between $\mathrm{HH}$ leaching volume and amount extracted (Fig. 9a,b). The HH leaching volume also exerts a control on the leachate $\varepsilon_{\mathrm{Nd}}$ values, which become more radiogenic for larger volumes (Fig. 9c). The REE patterns from experiment (v) are similar to those from experiment (iv) (Fig. 8gi cf. Fig. 8d-f), with the exception of the behaviour of the Ce anomaly, which is independent of the HH leaching volume (Fig. 8h,i) but dependent on the HH leaching time (Fig. 8e,f).

\section{DISCUSSION}

\subsection{Extraction of REE's from deep sea sediments}

\subsubsection{Dissolution of multiple phases under a kinetic control}

A number of processes may be involved in the transfer of elements from solid to solution, including rapid surface exchange, solid state diffusion across a developing leached residual layer or precipitating layer, steady state diffusion across such a layer, or congruent surface dissolution (e.g. Luce et al., 1972). Since different processes are expected to lead to differing temporal evolution of the solution chemistry, kinetic dissolution experiments can provide evidence on the mechanisms and rates of the processes involved. Here we attempt to extend such an approach, typically used for individual minerals, to the extraction of $\mathrm{Nd}$ and other elements from deep sea sediments, with the caveat that this may contain multiple phases that are extractible by acid-reductive leaching.

To first order, experiments (iii) and (iv) demonstrate a kinetic control on the Fe, Al and $\mathrm{Nd}$ release (Fig. 6). Whereas a control by surface reactions would lead to a linear relationship in concentration versus time, the observed relationship is parabolic (i.e. linear in concentration versus $V_{\text {time}}$ ), which implies a diffusional control (e.g. Luce et al., 1972). We suggest that such a control arises from the development of a leached layer or a secondary precipitating layer (e.g. Luce et al., 1972). Alternatively, preferential dissolution of fine particles could lead to a decrease in reactive surface area through time and also produce such a parabolic relationship (e.g. Holdren and Berner, 1979). 
The co-variation between $\mathrm{Fe}$ and $\mathrm{Nd}$ (Fig. 7a) and between $\mathrm{Al}$ and $\mathrm{Nd}$ (Fig. 7b) in the non-decarbonated leachates of experiment (iii) is consistent with an association of $\mathrm{Nd}$ with an $\mathrm{Fe}$ - and Al-rich phase. Such a phase is dissolved to a greater extent with a longer $\mathrm{HH}$ leaching time (Fig. 6a,b), over a timescale consistent with observations in iron extraction experiments by Tessier et al. (1979). However, the significant non-zero intercepts on plots of $\mathrm{Nd}$ against

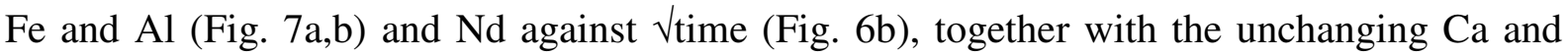
Mn concentrations with $\mathrm{HH}$ leaching time (Fig. 6a), indicates an incongruent nature to the dissolution. This could be attributed to incongruent dissolution of one phase but, given the close linear relationships between $\mathrm{Nd}, \mathrm{Fe}$ and $\mathrm{Al}$ (Fig. 7a,b), we consider this to be unlikely and instead suggest that it records the largely congruent dissolution of multiple phases with different reactivities (Moller and Giese, 1997). Around two thirds of the extractible $\mathrm{Nd}$ appears to be associated with a $\mathrm{Ca}$ - and/or Mn-rich phase which reacts rapidly and completely in less than 30 minutes (the time of the shortest experiment), thereby explaining the significant intercepts for these elements on the kinetic plots (Figs. 6a,b), while the remainder is associated with the slowly-reacting $\mathrm{Fe}$ - and Al-rich phase.

This kinetic control on the leaching is also recorded by the REE patterns from experiment (iii) (Fig. 8a-c), which provide further evidence on the phase associations of the extracted Nd. Our expectation (from Figs. 6 and 7) is for a rapid and complete extraction of REE's from a Ca- and Mn-rich phase (in under 30 minutes), and the slower removal of REE's from an Fe- and Al-rich phase (over the course of 8 hours), so that the REE patterns from longer leaching times should record an increasing proportion of REE's from the Fe- and Alrich phase. The REE pattern of the 30 minute leach (Fig. 8c) should provide a reasonable estimate of the REE pattern of the fast-reacting phase, and this is consistent with the REE pattern of uncleaned sedimentary foraminifera (see Fig. 5b). Rare earth elements in sedimentary foraminifera have been shown to be carried by authigenic nano-phases (Palmer, 1985; Palmer and Elderfield, 1986; Roberts et al., 2012; Tachikawa et al., 2013), and in the case of WIND 24B this probably represents a Mn oxide phase. Subtracting the REE concentrations of the shortest duration leach (30 minutes) from those of the longest duration leach (480 minutes) allows us to characterise the REE pattern of the slow-reacting Fe- and Alrich phase (Fig. 8c), and a comparison to the REE patterns of USGS ferromanganese nodule standards indicates that this can be well described as an iron oxide phase precipitated from seawater.

Experiment (ii) demonstrates the effect of the preceding acetic acid leaching on the subsequent HH leaching, and experiment (iv) investigates the kinetics of the leaching for such decarbonated sediments. Decarbonation leads to a reduction in the amount of Ca extracted by $\mathrm{HH}$ leaching (by over 200 times), and in the amount of $\mathrm{Nd}$ (by over 20 times), but little change in Fe or Mn (Fig. 4a). The Ca reduction records the removal of carbonate, whereas the constancy of $\mathrm{Fe}$ and $\mathrm{Mn}$ concentrations suggests that ferromanganese oxides are largely insoluble in buffered acetic acid and are not removed during the acetic acid leaching. Alternatively, the $\mathrm{Fe}$ and $\mathrm{Mn}$ concentrations in the $\mathrm{HH}$ leachates may be limited by the kinetics of the dissolution during $\mathrm{HH}$ leaching, at least for Fe (Fig. 6a,d), in which case this may not provide a strong constraint on the extent of their removal during the acetic acid 
leaching. The Nd-Fe crossplot from experiment (iv) (Fig. 7c) demonstrates that the $\mathrm{Nd}$ appears to be associated with an Fe-rich phase as in experiment (ii), but there is no longer a significant y-intercept in this plot (cf. Fig. 7a), which we attribute to the removal of the Mnassociated phase during the prior acetic acid leaching (Fig. 4a). This is also consistent with the approximately zero y-intercept for $\mathrm{Nd}$ in the kinetic plot (Fig. 6e cf. Fig. 6b).

Two lines of evidence lead us to question the nature of the Fe-rich phase(s) extracted in experiment (iv). Firstly, the gradient in the Nd-Fe crossplot is lower for experiment (iv) (Fig. 7c) than for experiment (iii) (Fig. 7a), which may indicate that a different Fe-rich phase is being attacked, or alternatively that $\mathrm{Nd}$ has been preferentially lost from the Fe-rich phase during the acetic acid leaching. Secondly, the REE patterns in experiment (iv) (Fig. 8d-f), and similarly in stage 2 of experiment (ii) (Fig. 5), differ from the expected pattern for ferromanganese oxides and instead closely resemble the REE patterns of the detrital sediment in this core (Fig. 8f). The presence of a positive Ce anomaly (Figs. 5b, 8f) and unchanging Fe and $\mathrm{Mn}$ concentrations as a function of the acetic acid leaching history (Fig. 4a) suggest that it may still be an oxide phase that is dissolved, but in that case the REE patterns suggest that its REE composition has been modified by interaction with the detrital sediment. A role for a detrital sediment component is further supported by the higher Al content (Fig. 6d cf. Fig. 6a) and the order of magnitude lower Nd-Al slope (Fig. 7d cf. Fig. 7b).

\subsubsection{Nd isotopic evidence on the phases involved}

The insensitivity of leachate $\varepsilon_{\mathrm{Nd}}$ compositions to the $\mathrm{HH}$ leaching time in experiment (iii) on non-decarbonated sediment (Fig. 6c) indicates that the two phases from which $\mathrm{Nd}$ is extracted (inferred to be Mn oxides and Fe oxides) have the same or similar $\varepsilon_{\mathrm{Nd}}$ compositions $(-11.0$ to -11.5$)$ and the agreement with $\varepsilon_{\mathrm{Nd}}$ from uncleaned foraminifera implies an authigenic origin. The REE budget of uncleaned sedimentary planktonic foraminifera is dominated by authigenic coatings derived from bottom water (Palmer, 1985; Palmer and Elderfield, 1986; Roberts et al., 2012) that likely comprise iron (oxyhydr)oxides, manganese oxides and/or manganese carbonates (e.g. Boyle, 1983; Haley et al., 2005; Pena et al., 2008; Tachikawa et al., 2013). We suggest that such Mn coatings associated with foraminifera (or with other finer-grained carbonate material within the core) represent the phase that is rapidly dissolved during experiment (iii), and that these are removed by the acetic acid leaching during stage 1 of experiment (ii). In contrast, the slower-reacting Fe oxide phase may not be associated with foraminifera (for example, it may be present as fine oxide particulates or contained within coatings on other sediment grains) and appears to survive the acetic acid leaching.

In experiment (iv) on decarbonated sediments, the Fe-rich leachates have $\varepsilon_{\mathrm{Nd}}$ compositions as high as $\sim-6$, which is significantly more radiogenic than both the authigenic phases $\left(\varepsilon_{\mathrm{Nd}} \sim-11\right)$ and the detrital sediment residue $\left(\varepsilon_{\mathrm{Nd}} \sim-15\right)$ (Fig. 6f). This supports our suggestion (Section 4.1.1) that this phase is different from the Fe-rich phase extracted during experiment (iii), and requires the presence within the sediment of a reactive phase with a radiogenic $\mathrm{Nd}$ isotopic composition. Volcanics from the Mascarene Plateau and/or Reunion may represent such a source (Fig. 4b) and this possibility is discussed further in Section 4.2.2. 
The change in $\varepsilon_{\mathrm{Nd}}$ compositions as a function of $\mathrm{HH}$ leaching time (experiment (iv); Fig. 6f) and $\mathrm{HH}$ leaching volume (experiment (v); Fig. 9c) also suggests the presence of multiple phases with differing isotopic compositions that are accessed to a different extent according to the leaching kinetics.

The sample size tests of experiment (i) on WIND 24B (Fig. 2) indicate a similar range of $\varepsilon_{\mathrm{Nd}}$ values as observed in experiments (ii-v), implying the same multiple sources of $\mathrm{Nd}$ as discussed above contribute to those leachates. In this context, experiment (i) provides a demonstration of similar behaviour to that observed in WIND 24B in the other Mascarene Basin cores (WIND 28B, 32B) whereas in the Mozambique Basin sample (WIND 1B) there is no evidence for an additional radiogenic component (Fig. 2).

\subsubsection{Discrepancies between $\varepsilon_{N d}$ and REE patterns as source tracers}

In stage 1 of experiment (ii) and in experiment (iii), REE patterns and $\varepsilon_{\mathrm{Nd}}$ compositions provide consistent evidence on the sources of $\mathrm{Nd}$ to the leachates (Section 4.1.1-4.1.2). However, in the other experiments we observe examples of decoupled behaviour of $\varepsilon_{\mathrm{Nd}}$ and REE's. For example, in experiments (iv) and (v), REE patterns (Fig. 8d-i) are similar and largely unchanging (with time or volume), with the exception of the Ce anomaly (Fig. 8e cf. Fig. 8h), whereas $\varepsilon_{\mathrm{Nd}}$ shows significant variability. Since the $\varepsilon_{\mathrm{Nd}}$ composition changes independently of the Ce anomaly in experiment (v), this indicates that the differences in $\varepsilon_{\mathrm{Nd}}$ in experiments (iv) and (v) cannot be explained by mixing between phases with different $\mathrm{Ce}$ anomalies. Instead, we infer that the dissolution of the REE-containing phase is fast relative to the reduction of the $\mathrm{Ce}$, so that experiment (iv) (Fig. 8e,f) records a kinetic control on the Ce anomaly, and we thereby exclude the use of the Ce anomaly as a simple source tracer. Furthermore, considering the trivalent REE's, the REE composition of these leachates is similar to the REE composition of the detrital sediment (Fig. 8f), whereas the $\varepsilon_{\mathrm{Nd}}$ compositions are different (Fig. 6f), which provides a second example of the discrepancy between the evidence from $\mathrm{Nd}$ isotopes and REE's.

The above observations can be reconciled if two different phases are being dissolved at different rates, while surface or solution complexation is controlling the REE patterns, making them largely independent of the source of REE's. Alternatively, we may consider a control by the dissolution of one phase (controlling REE patterns) and ongoing exchange with a second phase (controlling $\varepsilon_{\mathrm{Nd}}$ ). In either case, this suggests that there are limitations on the use of REE patterns for assessing the source and/or phase association of REE's (and therefore $\left.\varepsilon_{\mathrm{Nd}}\right)$ in sequential extractions.

\subsubsection{Evidence for an exchange process}

In experiment (ii), acetic acid leaching affects the $\varepsilon_{\mathrm{Nd}}$ compositions of $\mathrm{HH}$ leachates during both stages 1 and 2 (Fig. 4b), whereas the Nd concentrations only change during stage 1 (Fig. 4a). Similarly, samples V2.2 and V2.7 have distinct $\varepsilon_{\mathrm{Nd}}$ compositions but similar Nd 
concentrations (Fig. 4). These two lines of evidence indicate that removal of an authigenic component during the decarbonation cannot be the only process that is occurring, and we suggest that there is a further exchange process occurring between the authigenic iron-rich component and the more radiogenic component (hereafter 'component C') that we have identified.

An exchange process requires that adsorption and desorption are occurring between the sediment and solution, which has been demonstrated for REE's under similar conditions to those used in our experiments (Sholkovitz, 1989; Bau, 1999). Our experiments were performed with solid/solution ratios 2-10 times higher than previously (e.g. Sholkovitz, 1989) and we might expect readsorption to be even more strongly favoured in this case. We also note that no chelating agent was used in our experiments (cf. Gutjahr et al., 2007). In this case, REE's associated with carbonates, ferromanganese oxides or component $\mathrm{C}$ that are liberated in acetic acid at $\mathrm{pH} 5$ (by dissolution and/or desorption) could be readsorbed by a combination of these same or different phases, before subsequently being extracted by $\mathrm{HH}$ leaching at $\mathrm{pH} 2$ when phases are dissolved. Such a mechanism could apply during stage 1 of the acetic acid leaching, while some phases are also selectively removed, and during stage 2, when significant phase removal is not occurring (Fig. 4a). In each case, continuous desorption and adsorption of $\mathrm{Nd}$ between the authigenic iron-rich component and the more radiogenic component $\mathrm{C}$ could explain changes in the $\varepsilon_{\mathrm{Nd}}$ composition of the $\mathrm{HH}$ leachates (Fig. 4b).

We have provided strong evidence that readsorption can effectively transfer REE's between different phase associations during sequential leaching. This implies that the REE patterns of the Nd sources can be fractionated by this process (Sholkovitz, 1989) and become decoupled from $\varepsilon_{\mathrm{Nd}}$ behaviour (Section 4.1.3). The use of a chelating agent such as Na-EDTA (Gutjahr et al., 2007) could help to reduce readsorption and improve the selectivity of sequential leaching processes for REE's, and their isotopes, as well as other particle-reactive elements.

\subsection{Implications for the boundary exchange process}

Deep sea sediments contain multiple components with potentially differing reactivities towards boundary exchange, which is well represented by our use of core material from the Mozambique and Mascarene Basins characterised by different sedimentological inputs. The use of acidic and reducing leaching solutions is appropriate for investigating processes expected to be occurring in pore waters, where acidity is generated by the decomposition of organic matter and microbial reduction can produce sharp redox gradients. In contrast, such reducing conditions may not be appropriate for investigating processes occurring above the sediment-water interface in oxygenated bottom waters. The acidity of $\mathrm{pH} 2$ used during the $\mathrm{HH}$ leaching is a more extreme scenario than expected for the deep ocean, but this leaching involves proton diffusion and replacement in the solid, which is fundamentally the same process that is likely to be occurring in the oceans where the $\mathrm{pH}$ is below 8.5. Given the sensitivity of protonation kinetics to both temperature and $\mathrm{pH}$ (Casey and Ludwig, 1995; Sverdrup and Warfvinge, 1995), the conditions of our experiments allow us to investigate 
processes that might occur over months to millennia in pore waters over a timescale that is more accessible to laboratory experiments. For example, mineral dissolution rates are expected to be at least two orders of magnitude faster at $\mathrm{pH} 2$ than at a neutral $\mathrm{pH}$ (Casey and Ludwig, 1995).

We emphasise that our experimental conditions do not attempt to replicate the natural boundary exchange. For example, the chemistry of the leaching solutions is not directly comparable to seawater (although the ionic strength is similar) which may lead to different complexation of elements in solution. In particular, one factor not considered here is the possible role of organic ligands in stabilising elements in natural waters (e.g. Mendez et al., 2010). More generally, our experiments present a chemical perspective and do not directly assess the role that biology might play in boundary exchange. However, in this respect it is interesting to note that a similar reductive leaching procedure is widely used to assess the labile (bio-available) iron contained in marine particulate material (Berger et al., 2008), although the micro-environment in which such microbial reduction is occurring will be different from the relatively open environment of our experiments.

To summarise, we suggest that our experiments provide an appropriate, but not direct, analogue for boundary exchange processes and can provide first order insights into the fundamental chemical exchanges occurring in deep sea sediments.

\subsubsection{Extraction of an authigenic component}

Acid-reductive leaching of sediments accesses multiple phases containing $\mathrm{Nd}$ from different sources and these phases have differing reactivities. These include Nd from nanophases associated with carbonate and $\mathrm{Nd}$ associated with ferromanganese oxides (e.g. Fig. $8 \mathrm{c}$ ), and in the case of WIND 24B, an $\varepsilon_{\mathrm{Nd}}$ composition of $\sim-11$ for these phases is in agreement with the $\varepsilon_{\mathrm{Nd}}$ composition of uncleaned foraminifera (Figs. 4b, 6c). Uncleaned foraminifera are considered to represent the authigenic $\varepsilon_{\mathrm{Nd}}$ composition (Palmer and Elderfield, 1985; Roberts et al., 2012), which indicates an authigenic origin for these extracted components. Boundary exchange involving such components derived from local bottom water is expected to have a minimal isotopic effect. Nevertheless, since these represent the most easily liberated components (Fig. 4), their dissolution could influence seawater $\mathrm{Nd}$ concentrations without significantly changing $\varepsilon_{\mathrm{Nd}}$ composition and could also provide a buffering influence on the $\mathrm{Nd}$ isotopic effect of boundary exchange from other detrital or volcanic components.

\subsubsection{Preferential dissolution of a volcanic component}

More significantly, the change in $\varepsilon_{\mathrm{Nd}}$ as a function of the acetic acid leaching history (Fig. 4b), the HH leaching time (Fig. 6f) and the HH leaching volume (Fig. 9c), and the different $\varepsilon_{\mathrm{Nd}}$ from different sample sizes (Fig. 2), requires that there is at least one further component within the sediment with a different $\varepsilon_{\mathrm{Nd}}$ composition that is extractible by the $\mathrm{HH}$ 
leaching. This component $\mathrm{C}$ generates more radiogenic $\varepsilon_{\mathrm{Nd}}$ compositions than the authigenic components in all studied cores of the Mascarene Basin and cannot correspond to the bulk detrital sediment, which is always less radiogenic (Fig. 2). In the western Indian Ocean, volcanics such as those from the Mascarene Plateau and Reunion (Fig. 1) represent possible sources of a radiogenic $\varepsilon_{\mathrm{Nd}}$ component (Fig. $4 \mathrm{~b}$ ). We therefore suggest that component $\mathrm{C}$ is a minor volcanic component that preferentially contributes to the leachates, whereas the detrital components that are sourced from Madagascar and dominate the detrital sediment $\mathrm{Nd}$ budget (Wilson et al., 2012; Fig. 4b) are relatively inert during the leaching.

The core site WIND 1B in the Mozambique Basin does not require a contribution from the component $\mathrm{C}$ (Fig. 2). This difference cannot be explained by differences in detrital sediment content, since WIND 1B has a carbonate content intermediate between those of the Mascarene Basin cores (Table 1). It may, therefore, record a geographic control on the abundance of component $\mathrm{C}$ within the detrital fraction, which might reflect the presence of local volcanic sources to the Mascarene Basin (Fig. 1) and an absence of such sources to the Mozambique Basin.

A mass balance approach also provides support to our suggestion that component $\mathrm{C}$ is a minor volcanic component. The most radiogenic leachate from experiment (ii) on WIND $24 \mathrm{~B}$ has an $\varepsilon_{\mathrm{Nd}}$ composition of -6.6 , which can be modelled as a mixture between the authigenic composition (-11.5) and a basaltic volcanic composition (+5) (Fig. 4b). Using data from Table 4 (converting from wet weights to dry weights using a conversion factor of 3 that was determined experimentally on leached material from WIND 24B), we determine that only $\sim 1 \%$ of the total detrital $\mathrm{Nd}$ budget is required to be accessed. Based on the assumption that the bulk detrital sediment at WIND 24B $\left(\varepsilon_{\mathrm{Nd}}=-15.4\right)$ is a mixture between Madagascan (18.3 ) and volcanic (+5) sources (see Fig. $4 \mathrm{~b}$ ), the volcanics contribute $\sim 12 \%$ to the bulk detrital sediment $\mathrm{Nd}$ budget. Therefore, if contamination of the leachates only occurs from the volcanic component, $\sim 8 \%$ dissolution of this phase is required, in good agreement with recent studies on the dissolution of volcanic materials (Jones et al., 2012). Based on the same approach, the small samples of experiment (i) on WIND 24B also require $\sim 8 \%$ dissolution of this volcanic phase, while comparable calculations for small samples from WIND 28B and WIND 32B are also consistent with $\sim 5-10 \%$ dissolution. The similarity in these results between different experiments for WIND 24B, and between sites with different detrital and authigenic $\mathrm{Nd}$ isotope compositions and budgets, provides further evidence for a kinetic control on the dissolution of volcanic materials and supports the ubiquitous presence and reactivity of such a volcanic phase in the Mascarene Basin. We also emphasise that this restricts the extent of dissolution that is occurring from the remaining detrital sediment components to be significantly less than $1 \%$.

Globally, there are a number of other locations where acid-reductive leaching of sediments has produced $\varepsilon_{\mathrm{Nd}}$ values that are more radiogenic than the local bottom water or the inferred authigenic composition (e.g. Tachikawa et al., 2004; Roberts et al., 2010; Stumpf et al., 2010; Elmore et al., 2011; Piotrowski et al., 2012). Although these studies have not all reported the composition of the associated detrital silicates, there is also some evidence for a bias towards extracting a radiogenic $\mathrm{Nd}$ component from the detrital sediment (e.g. 
Tachikawa et al., 2004). This suggests that the incongruent dissolution of a reactive Nd phase from marine sediments may be a fairly widespread phenomenon, and that the bias may generally be towards extracting a radiogenic $\mathrm{Nd}$ component. This is consistent with a greater reactivity of basaltic material compared to continental/granitic material (e.g. Dessert et al., 2003) and has previously been suggested in a shelf setting (Charbonnier et al., 2012). Overall, this would imply that boundary exchange is relatively more important for the deep Pacific Ocean than other ocean basins because of the abundance of a widespread volcanic component, as previously suggested by modelling (Jones et al. 2008). More work addressing the reactivity of different phases towards boundary exchange is recommended and, more speculatively, we suggest that sediment leaching may provide a useful tool for mapping the volcanic contribution to a sediment pile and for constraining volcanic inputs to seawater.

\subsubsection{Sediment reactivity related to ageing}

Whereas in this study we have suggested that the unradiogenic detrital clay component in the Mascarene Basin is relatively inert, we have previously provided evidence for boundary exchange from an unradiogenic component at sites along the Madagascan margin including WIND 24B (Wilson et al., 2012). We suggest that this discrepancy reflects a highly reactive unradiogenic component that is derived from Madagascan weathering and delivered rapidly to the deep ocean across a narrow shelf, leading to boundary exchange along the deep Madagascan margin. Such a component may not then have survived into the sedimentary record that was sampled for the leaching experiments. Indeed, we previously suggested (Wilson et al., 2012) that such a component does not survive to reach WIND 32B during northward transport by deep ocean currents, whereas detrital sediment from Madagascar is transported that far. The lack of reactivity of any detrital components in the Mozambique Basin sediments (WIND 1B) compared to the Mascarene Basin (WIND 24B, 28B and 32B) (Fig. 2) may also provide evidence on a similar control of particle lability relating to ageing, since WIND 1B is further from local sediment sources than the Mascarene Basin cores (Fig. 1).

Solution/solid ratios appear to be an important control on $\mathrm{Nd}$ release, with more radiogenic $\varepsilon_{\mathrm{Nd}}$ compositions being released for higher solution/solid ratios and for longer leaching times (Figs. 2, 4b, 6f, 9c). The implication here is that after ageing of sediments in the deep ocean, the volcanic component may become a more important contributor to the boundary exchange. Therefore, factors such as proximity to local sediment inputs and total sedimentation rates might control the extent of this ageing and influence the isotopic effect of the boundary exchange.

\subsubsection{Control on REE patterns}

The reproducibility and constancy of REE patterns (e.g. Fig. 8f,i) while $\varepsilon_{\mathrm{Nd}}$ changes suggests that a combination of surface and/or solution complexation may be important controls on the transfer of $\mathrm{Nd}$ and other REE's between the particulate and dissolved 
components. The nature of the solution complexation in our experiments is uncertain, while in the real world it is likely that there will be an additional role for organic colloids in such a complexation and stabilisation process. This requires further investigation if we are to better understand both the elemental and isotopic effects of boundary exchange.

\subsubsection{Insights for modelling boundary exchange}

The above observations have significant implications for the quantification of boundary exchange in modelling studies. To date, it has been assumed that the bulk detrital sediment $\varepsilon_{\mathrm{Nd}}$ composition represents the isotopic composition that will contribute to boundary exchange (e.g. Lacan and Jeandel, 2005; Arsouze et al., 2009; Rempfer et al., 2011). Instead, we suggest that detrital sediment will often be derived from a mixture of sources and that these may not contribute equally to the boundary exchange. For example, a volcanic component appears likely to contribute preferentially over a detrital clay component. Therefore, the use of the bulk detrital sediment $\varepsilon_{\mathrm{Nd}}$ as an indicator of the boundary exchange $\varepsilon_{\mathrm{Nd}}$ input may be seriously in error in some locations in the global oceans, as a function of the differing mineralogical components present in the sediments.

We also suggest that there may be a role for the lability of the different components of the detrital sediments related to their input function, transport history and ageing in the deep sea setting. If the role of sediment reactivity or lability is to be incorporated into ocean geochemical models it will become necessary to model the origin and age distribution of sediment particles in the deep ocean, while further experimental work is also required in order to place stronger constraints on the importance of this process.

Models incorporating boundary exchange have typically applied a boundary exchange flux along continental margins defined by a bathymetry of 0-3000 m (Arsouze et al., 2007, 2009; Rempfer et al., 2011), and either used a globally uniform flux (Rempfer et al., 2011) or a geographically independent but water depth-dependent flux (Arsouze et al., 2007, 2009). However, if different sediment components have differing reactivity during boundary exchange processes (related to mineralogy and/or sediment ageing), there may be significant geographic variability in the boundary exchange flux as well as its isotopic composition. Our study therefore provides some experimental support for an approach that links boundary exchange flux with the mineralogical composition of the sediments. This suggests that the mineralogy as well as the $\varepsilon_{\mathrm{Nd}}$ of the boundary source should be quantified and input to models, although scaling the boundary exchange flux with the sediment $\varepsilon_{\mathrm{Nd}}$ composition may represent a simple first order approach.

\subsection{Implications for recovering the "past seawater" $\varepsilon_{\mathrm{Nd}}$ by leaching}

Our improved understanding of the leaching process provides a basis for re-addressing the sediment leaching methods used to recover the authigenic or "past seawater" $\varepsilon_{\mathrm{Nd}}$ composition for paleoceanographic studies. In the western Indian Ocean, reported deep water 
$\varepsilon_{\mathrm{Nd}}$ compositions are in the range of -7.7 to -10.5 (Bertram and Elderfield, 1993) but there is no local bottom water data from our studied sites. We have previously demonstrated that boundary exchange may be important in modifying bottom water $\varepsilon_{\mathrm{Nd}}$ in this region (Wilson et al., 2012) such that comparison to the open ocean water profiles of Bertram and Elderfield (1993) must be made with caution. However, recent studies indicate that uncleaned sedimentary planktonic foraminifera reliably record bottom water $\varepsilon_{\mathrm{Nd}}$ compositions in most settings (Elmore et al., 2011; Piotrowski et al., 2012; Roberts et al., 2012; Tachikawa et al., 2013). We therefore use uncleaned foraminifera as a proxy for the local bottom water $\varepsilon_{\mathrm{Nd}}$ compositions at our sites (Fig. 2), while noting reasonable agreement with the Bertram and Elderfield (1993) data. Our specific aim is therefore to investigate the recovery of an $\varepsilon_{\mathrm{Nd}}$ signal from the mixed components in bulk sediment that is in agreement with the foraminiferal $\varepsilon_{\mathrm{Nd}}$, rather than to assess the sources or mechanisms of $\mathrm{Nd}$ incorporation into foraminifera.

\subsubsection{Evidence for non-selectivity}

Our leaching experiments clearly demonstrate the potential for non-selectivity during sediment leaching (Figs. 2, 4b, 6f, 9c) but the controls on the leachate $\varepsilon_{\mathrm{Nd}}$ composition are highly systematic. In particular, we show that in the cases of non-decarbonated sediments (Fig. 6c) and 12-14 g samples that have undergone acetic acid leaching (Fig. 2) there is a good agreement between $\varepsilon_{\mathrm{Nd}}$ from $\mathrm{HH}$ leachates and $\varepsilon_{\mathrm{Nd}}$ from uncleaned foraminifera. Since the physical separation of foraminifera from the mixture of components in bulk sediment should remove or reduce the effect of non-selectivity that could affect bulk sediment leachates (Roberts et al., 2010; Elmore et al., 2011), this agreement provides an indication of the successful extraction of the authigenic component without significant detrital or volcanic contamination. In contrast, $\mathrm{HH}$ leaching of samples after significant acetic acid leaching (Figs. 4b, 6f), and the use of 4-5 g samples that have been acetic acid leached (Fig. 2), leads to significant discrepancies with foraminiferal $\varepsilon_{\mathrm{Nd}}$ and indicates that $\mathrm{Nd}$ is also being extracted from detrital and/or volcanic sources.

\subsubsection{Sources of Nd and processes during leaching}

A schematic visualisation of the extraction of $\mathrm{Nd}$ from deep sea sediments during the reductive leaching process is shown in Fig. 10. Below we summarise the processes that influence the leachate compositions, focusing particularly on the recovery of the authigenic $\varepsilon_{\mathrm{Nd}}$ composition.

a) Sediment leachates with little or no prior decarbonation record the same $\varepsilon_{\mathrm{Nd}}$ and similar REE patterns to uncleaned foraminifera (Figs. 4b, 5b), providing evidence that these methods dominantly extract the same authigenic phase (likely a Mn oxide) and that this phase dominates the extractible Nd budget in the sediments. 
b) The reduction by more than an order of magnitude in the amount of extractible $\mathrm{Nd}$ as decarbonation progresses (Fig. 4a) indicates that the acetic acid leaching leads to significant removal of the authigenic Mn-associated component (Fig. 10) and the subsequent $\mathrm{HH}$ leachates are more susceptible to contamination by the volcanic component (Figs. 4b, 6f).

c) Since leachate $\varepsilon_{\mathrm{Nd}}$ compositions continue to change with continued acetic acid leaching after decarbonation, while the $\mathrm{Nd}$ and $\mathrm{Ca}$ concentrations are unchanging (Fig. 4), this implies that the volcanic component is involved in exchange with the Fe oxide phase (Section 4.1.4; Fig. 10).

d) There is always a kinetic control on the HH leaching. In non-decarbonated sediments, the authigenic Mn-associated phase reacts almost instantaneously, while an authigenic iron oxide phase reacts more slowly over a period of hours (Figs. 6a-c, 8c). In decarbonated sediments, the reaction kinetics are slower, with contributions from an iron oxide phase (which may have already exchanged with the volcanic component) and perhaps the volcanic component itself (Fig. 6d-f).

e) Divergence away from the expected authigenic $\varepsilon_{\mathrm{Nd}}$ composition towards the composition of volcanics occurs with increasing solution/solid ratios (Fig. 2), reflecting a combination of processes during the acetic acid leaching (Fig. 4b) and the HH leaching (Fig. 9). In general, increasing solution/solid ratios lead to an increased accessibility of volcanics.

\subsubsection{Recommended leaching procedure}

We suggest that sediment leaching should be considered as a chemical reaction that must be evaluated on a site-by-site basis rather than as a simple method that can be uniformly applied. In general, we propose that small solution/solid ratios should be used during the $\mathrm{HH}$ leaching (i.e. short times and small leaching volumes relative to the sample size) in order to take advantage of the differences in reaction kinetics between authigenic and contaminant phases. This study therefore provides experimental support for our previous observation that reliable sediment leachate $\varepsilon_{\mathrm{Nd}}$ data can be obtained from throughout the Mascarene Basin with the use of small solution/solid ratios (Wilson et al., 2012). Whereas the use of 12-14 $\mathrm{g}$ samples may not always be possible or economic, appropriate solution/solid ratios could potentially be achieved using smaller samples, given appropriate leaching times and volumes. However, the quantitative assessment of appropriate solution/solid ratios is almost certainly sample and site specific, since it will depend on the components present in the sediment. For example, sediment leachate $\varepsilon_{\mathrm{Nd}}$ values in WIND $1 \mathrm{~B}$ are insensitive to the leaching methodology (Fig. 2), which may be due to an absence of reactive volcanic components.

We further suggest that the acetic acid leaching step is fundamentally not required and that $\mathrm{HH}$ leaching of non-decarbonated sediments may provide the most reliable approach, and one that may be more suitable for smaller sample sizes. Our interpretation that leaching of non-decarbonated sediments recovers a bottom water $\varepsilon_{\mathrm{Nd}}$ signal is based on the validation of uncleaned foraminiferal $\varepsilon_{\mathrm{Nd}}$ as a bottom water $\varepsilon_{\mathrm{Nd}}$ carrier at sites elsewhere (Palmer and 
Elderfield, 1985; Elmore et al., 2011; Piotrowski et al., 2012) and the evidence that any surface-derived $\mathrm{Nd}$ present within the foraminiferal carbonate lattice makes up only a minor part of its Nd budget (Palmer, 1985; Roberts et al., 2012; Tachikawa et al., 2013). Any possible benefit gained from the removal of surface-derived $\mathrm{Nd}$ using decarbonation in acetic acid would appear to be outweighed by the loss of the Mn-associated authigenic phase (Section 4.1.1; Fig. 10) and Nd exchange with reactive non-authigenic components (Section 4.1.4; Fig. 10) where they are present.

Our suggestion to use $\mathrm{HH}$ leaching without decarbonation is similar to the approach of Gourlan et al. (2008; 2010), who used acetic acid leaching on non-decarbonated sediments, except that those authors suggested they were recording a signal from surface to intermediate water depths $(0-1000 \mathrm{~m})$. Our study supports the general reliability of the Gourlan et al. (2008; 2010) approach for recovering an authigenic $\varepsilon_{\mathrm{Nd}}$ signal, with two caveats. Firstly, we suggest that their signal is likely to correspond to dominantly bottom water contributions rather than surface water. This is supported by the excellent agreement between their leaching method and the Bayon et al. (2002) HH leaching method (proposed to record bottom water $\varepsilon_{\mathrm{Nd}}$ ) at their sites (Gourlan et al., 2008; 2010), but should be tested in locations with strong vertical $\varepsilon_{\mathrm{Nd}}$ gradients in the water column. Secondly, the potential for contamination by nonauthigenic reactive components still needs to be considered on a site-by-site basis in locations where such components may be abundant within the sediment, such as proximal to volcanic islands or in regions of significant ice-rafting which could deliver reactive glacial flour.

We finally note that our observations are based on coretop sediments, and that diagenesis must be considered if such approaches are applied to downcore studies. Where the sediment column has remained in oxic conditions, we expect our conclusions to remain correct, and the consistency in $\varepsilon_{\mathrm{Nd}}$ values between foraminifera and non-decarbonated leachates through the top $1 \mathrm{~m}$ in core WIND 28K (Wilson et al., 2012) appears to support this. However, where anoxic conditions have been reached and ferromanganese oxides have been reduced (Reimers et al., 1996), our conclusions must be re-assessed.

\subsubsection{Challenges for the geochemical validation of leachate $\varepsilon_{N d}$ data}

A number of geochemical approaches have been proposed for evaluating the authigenic origin of leachate $\varepsilon_{\mathrm{Nd}}$ data, including Sr isotopes (Rutberg et al., 2000), REE patterns (Bayon et al., 2002) and $\mathrm{Al} / \mathrm{Nd}$ ratios (Gutjahr et al., 2007), and recently critically reviewed (Martin et al., 2010). Since our study provides examples of leachate $\varepsilon_{\mathrm{Nd}}$ data that does not always represent an authigenic signal, our evidence further constrains the use of REE patterns and $\mathrm{Al} / \mathrm{Nd}$ for this question.

In some cases, differences in REE patterns coincide with differences in $\varepsilon_{\mathrm{Nd}}$, particularly considering non-decarbonated versus decarbonated leachates (e.g. Fig. 8a-c cf. Fig. 8d-f; Fig. 3g,h), but in a number of cases we provide evidence for decoupling of $\mathrm{Nd}$ isotopes and REE patterns (see Section 4.1.3). Our inference that surface exchange processes 
and solution complexation are important controls on the REE patterns clearly complicates their use as a source tracer for the origin of leached $\mathrm{Nd}$.

Our observations on the utility of $\mathrm{Al} / \mathrm{Nd}$ ratios are similarly contradictory. Nondecarbonated sediment leachates from experiment (iii) have low Al/Nd ratios (10-23; Table 4) that are consistent with an authigenic origin (Gutjahr et al., 2007; Martin et al., 2010), and in experiment (ii), $\mathrm{Al} / \mathrm{Nd}$ ratios increase from 30 to 850 with progressive acetic acid leaching during stage 1 (Table 4) while $\varepsilon_{\mathrm{Nd}}$ shifts away from the authigenic composition (Fig. 4). However, during stage 2 of experiment (ii), Al/Nd remains constant at 850-950 (compared to detrital fraction $\mathrm{Al} / \mathrm{Nd}$ values $~ 3800$; Table 4) while $\varepsilon_{\mathrm{Nd}}$ continues to evolve (Fig. 4), evidencing that $\mathrm{Nd}$ is exchanging (Section 4.1.4) independently of this proposed indicator of detrital contamination. Another inconsistency arises during experiment (iv), in which $\varepsilon_{\mathrm{Nd}}$ shifts further away from seawater values as the HH leaching time is increased (Fig. 6f), while the $\mathrm{Al} / \mathrm{Nd}$ ratios instead decrease (Table 4). Finally, we note that in the sample size tests on WIND 24B (Fig. 2), both 12-14 g samples (recording authigenic $\varepsilon_{\mathrm{Nd}}$ values) and 4-5 g samples (recording contaminated $\varepsilon_{\mathrm{Nd}}$ values) yield similar Al/Nd ratios ( 800-900; Table 4), indicating a decoupling of chemistry and $\mathrm{Nd}$ isotopes, as was also observed for their REE patterns (Fig. 3c,d). It is clear that while $\mathrm{Nd} / \mathrm{Al}$ ratios may detect contributions from the dissolution of Al-rich phases such as clays, they may also be influenced by readsorption.

We therefore suggest that comparison with the $\varepsilon_{\mathrm{Nd}}$ composition of uncleaned foraminifera or fish teeth may provide the best means of validating the authigenic origin of bulk sediment leachate $\varepsilon_{\mathrm{Nd}}$ data (e.g. Martin et al., 2010; Gutjahr and Lippold, 2011; Piotrowski et al., 2012). Whereas foraminifera or fish teeth should be less sensitive to detrital contamination, sediment leaching for $\mathrm{Nd}$ isotopes has the benefit of rapid sample throughput, the generation of higher resolution records, and the potential to be applied in locations in which foraminifera are absent. Therefore, the two approaches are complementary and the improved understanding of sediment leaching arising from this study should prove to be valuable.

\section{CONCLUSIONS}

Acid-reductive sediment leaching experiments provide evidence on the liberation of $\mathrm{Nd}$ (and other REE's) from ocean sediments, including phase association and reactivity, with implications for the boundary exchange process in the modern and past oceans, and for the recovery of the $\varepsilon_{\mathrm{Nd}}$ of the authigenic components.

Leachate chemistry and $\varepsilon_{\mathrm{Nd}}$ compositions are influenced by kinetics during the $\mathrm{HH}$ leaching, which allows us to separate the contributions of different phases. We provide evidence for both Mn-associated and iron oxide-associated authigenic Nd phases in deep sea sediments, as well as the presence of a minor acid-extractible radiogenic component that is more reactive than the bulk detrital sediment. Two main processes occur during acetic acid leaching: loss of an authigenic Mn-associated phase, and exchange between the remaining iron oxide phase and the minor non-authigenic radiogenic component. Three sites in the 
Mascarene Basin are sensitive to such a process, whereas one site in the Mozambique Basin appears to be insensitive to it, and we suggest that this reflects the presence or absence of reactive volcanics in the respective sediment piles.

Our experiments provide evidence that both dissolution and exchange processes could contribute towards boundary exchange, and that the detrital sediment $\varepsilon_{\mathrm{Nd}}$ composition will not always be representative of the $\mathrm{Nd}$ supplied to seawater by boundary exchange. Instead, $\mathrm{Nd}$ from both authigenic sources and from minor reactive components (such as volcanics) may preferentially contribute to the budget, which requires a revision to the approach typically used in studies modelling boundary exchange (Lacan and Jeandel, 2005; Arsouze et al., 2009; Rempfer et al., 2011). Particle lability related to transport and ageing in the deep sea, in addition to mineralogy, may be another important control on the $\mathrm{Nd}$ sources, while surface and/or solution complexation is likely to control the stabilisation of REE's during their transfer from solid to solution.

Systematic controls on the leachate chemistry and $\varepsilon_{\mathrm{Nd}}$ compositions from sample size, leaching time and volume lead us towards a better understanding of the leaching processes and systematics, with implications for the use of sediment leaching to reconstruct past seawater $\varepsilon_{\mathrm{Nd}}$ compositions. We demonstrate that the effects of readsorption and exchange need to be considered in the continued application of multi-step extraction techniques for REE's. A single reductive leaching step, without prior decarbonation, leads to the most reliable recovery of the authigenic $\varepsilon_{\mathrm{Nd}}$ compositions, and is consistent with foraminiferalbased approaches. An alternative acceptable approach uses low solution/solid ratios throughout the process, but appropriate solution/solid ratios will probably differ between sites and leaching experiments such as presented here may need to be conducted on a site-by-site basis. Overall, our observations are able to reconcile different methodologies used to reconstruct seawater $\varepsilon_{\mathrm{Nd}}$, including $\mathrm{HH}$ leaching (Rutberg et al., 2000; Bayon et al., 2002; Piotrowski et al., 2004; Gutjahr et al., 2007), acetic acid leaching (Gourlan et al., 2008) and uncleaned foraminifera (Roberts et al., 2010). While comparison to $\varepsilon_{\mathrm{Nd}}$ from uncleaned foraminifera appears to provide an appropriate tool for the validation of leachate data, the mechanistic lessons from our study will be important and should be further developed if sediment leaching is to be employed in carbonate-poor settings.

\section{ACKNOWLEDGEMENTS}

We thank Nick McCave for providing sediment samples and Jason Day for assistance with the Quadrupole ICP-MS measurements. We are also grateful to Marcus Gutjahr and two anonymous reviewers for their detailed reviews and constructive suggestions which helped improve the manuscript and to Derek Vance for his helpful advice and editorial handling. This study was supported by NERC grant NE/F006047/1, RG50124 LBZG/036 "Reconstructing past changes in global thermohaline circulation" to AMP/AG and a NERC studentship to DJW. 


\section{REFERENCES}

Amakawa, H., Sasaki, K., Ebihara, M. (2009) Nd isotopic composition in the central North Pacific. Geochim. Cosmochim. Acta 73, 4705-4719.

Arsouze, T., Dutay, J.C., Lacan, F., Jeandel, C. (2007) Modeling the neodymium isotopic composition with a global ocean circulation model. Chemical Geology 239, 165-177.

Arsouze, T., Dutay, J.C., Lacan, F., Jeandel, C. (2009) Reconstructing the Nd oceanic cycle using a coupled dynamical - biogeochemical model. Biogeosciences 6, 2829-2846.

Arsouze, T., Treguier, A.M., Peronne, S., Dutay, J.C., Lacan, F., Jeandel, C. (2010) Modeling the $\mathrm{Nd}$ isotopic composition in the North Atlantic basin using an eddypermitting model. Ocean Sci. 6, 789-797.

Bau, M. (1999) Scavenging of dissolved yttrium and rare earths by precipitating iron oxyhydroxide: Experimental evidence for Ce oxidation, Y-Ho fractionation, and lanthanide tetrad effect. Geochim. Cosmochim. Acta 63, 67-77.

Bayon, G., German, C.R., Boella, R.M., Milton, J.A., Taylor, R.N., Nesbitt, R.W. (2002) An improved method for extracting marine sediment fractions and its application to $\mathrm{Sr}$ and Nd isotopic analysis. Chemical Geology 187, 179-199.

Berger, C.J.M., Lippiatt, S.M., Lawrence, M.G., Bruland, K.W. (2008) Application of a chemical leach technique for estimating labile particulate aluminum, iron, and manganese in the Columbia River plume and coastal waters off Oregon and Washington. J. Geophys. Res.-Oceans 113, doi:10.1029/2007JC004703.

Bertram, C.J., Elderfield, H. (1993) The geochemical balance of the rare-earth elements and neodymium isotopes in the oceans. Geochim. Cosmochim. Acta 57, 1957-1986.

Bosch, D., Blichert-Toft, J., Moynier, F., Nelson, B.K., Telouk, P., Gillot, P.Y., Albarede, F. (2008) $\mathrm{Pb}$, Hf and $\mathrm{Nd}$ isotope compositions of the two Reunion volcanoes (Indian Ocean): A tale of two small-scale mantle "blobs"? Earth Planet. Sci. Lett. 265, 748-768.

Boyle, E.A. (1983) Manganese carbonate overgrowths on foraminifera tests. Geochim. Cosmochim. Acta 47, 1815-1819.

Broecker, W.S., Peng, T.H. (1982) Tracers in the Sea. Eldigio Press.

Carter, P., Vance, D., Hillenbrand, C.D., Smith, J.A., Shoosmith, D.R. (2012) The neodymium isotopic composition of waters masses in the eastern Pacific sector of the Southern Ocean. Geochim. Cosmochim. Acta 79, 41-59.

Casey, W.H., Ludwig, C. (1995) Silicate mineral dissolution as a ligand-exchange reaction. Rev. Miner. 31, 87-117.

Charbonnier, G., Puceat, E., Bayon, G., Desmares, D., Dera, G., Durlet, C., Deconinck, J.F., Amedro, F., Gourlan, A.T., Pellenard, P., Bomou, B. (2012) Reconstruction of the Nd isotope composition of seawater on epicontinental seas: Testing the potential of $\mathrm{Fe}-\mathrm{Mn}$ oxyhydroxide coatings on foraminifera tests for deep-time investigations. Geochim. Cosmochim. Acta 99, 39-56.

Chester, R., Hughes, M.J. (1967) A chemical technique for the separation of ferromanganese minerals, carbonate minerals and adsorbed trace elements from pelagic sediments. Chemical Geology 2, 249-262. 
Dessert, C., Dupre, B., Gaillardet, J., Louis, M. François, L.M., Allegre, C.J. (2003) Basalt weathering laws and the impact of basalt weathering on the global carbon cycle. Chemical Geology 202, 257-273.

Elmore, A.C., Piotrowski, A.M., Wright, J.D., Scrivner, A.E. (2011) Testing the extraction of past seawater Nd isotopic composition from North Atlantic deep sea sediments and foraminifera. Geochem. Geophys. Geosyst. 12, doi: 10.1029/2011 gc003741.

Frank, M. (2002) Radiogenic isotopes: Tracers of past ocean circulation and erosional input. Rev. Geophys. 40, 38.

Goldstein, S.J., Jacobsen, S.B. (1987) The Nd and Sr isotopic systematics of river-water dissolved material: Implications for the sources of $\mathrm{Nd}$ and $\mathrm{Sr}$ in seawater. Chemical Geology 66, 245-272.

Goldstein, S.L., Hemming, S.R. (2003) Long-lived isotopic tracers in oceanography, paleoceanography and ice sheet dynamics, in: Elderfield, H. (Ed.), The Oceans and Marine Geochemistry. Elsevier-Pergamon, Oxford, pp. 453-489.

Grasse, P., Stichel, T., Stumpf, R., Stramma, L., Frank, M. (2012) The distribution of neodymium isotopes and concentrations in the Eastern Equatorial Pacific: Water mass advection versus particle exchange. Earth Planet. Sci. Lett. 353, 198-207.

Gourlan, A.T., Meynadier, L., Allegre, C.J. (2008) Tectonically driven changes in the Indian Ocean circulation over the last $25 \mathrm{Ma}$ : Neodymium isotope evidence. Earth Planet. Sci. Lett. 267, 353-364.

Gourlan, A.T., Meynadier, L., Allegre, C.J., Tapponnier, P., Birck, J.L., Joron, J.L. (2010) Northern Hemisphere climate control of the Bengali rivers discharge during the past 4 Ma. Quat. Sci. Rev. 29, 2484-2498.

Gutjahr, M., Frank, M., Stirling, C.H., Klemm, V., van de Flierdt, T., Halliday, A.N. (2007) Reliable extraction of a deepwater trace metal isotope signal from Fe-Mn oxyhydroxide coatings of marine sediments. Chemical Geology 242, 351-370.

Gutjahr, M., Lippold, J. (2011) Early arrival of Southern Source Water in the deep North Atlantic prior to Heinrich event 2. Paleoceanography 26, doi: 10.1029/2011pa002114.

Haley, B.A., Klinkhammer, G.P., Mix, A.C. (2005) Revisiting the rare earth elements in foraminiferal tests. Earth Planet. Sci. Lett. 239, 79-97.

Holdren, G.R., Berner, R.A. (1979) Mechanism of feldspar weathering - I. Experimental studies. Geochim. Cosmochim. Acta 43, 1161-1171.

Jeandel, C., Bishop, J.K., Zindler, A. (1995) Exchange of neodymium and its isotopes between seawater and small and large particles in the Sargasso Sea. Geochim. Cosmochim. Acta 59, 535-547.

Jeandel, C., Peucker-Ehrenbrink, B., Jones, M.T., Pearce, C.R., Oelkers, E.H., Godderis, Y., Lacan, F., Aumont, O., Arsouze, T. (2011) Ocean margins: the missing term for oceanic element budgets? EOS Transactions American Geophysical Union 92, 217-218.

Jeandel, C., Thouron, D., Fieux, M. (1998) Concentrations and isotopic compositions of neodymium in the eastern Indian Ocean and Indonesian straits. Geochim. Cosmochim. Acta 62, 2597-2607.

Jones, K.M., Khatiwala, S.P., Goldstein, S.L., Hemming, S.R., van de Flierdt, T. (2008) Modeling the distribution of $\mathrm{Nd}$ isotopes in the oceans using an ocean general circulation model. Earth Planet. Sci. Lett. 272, 610-619. 
Jones, M.T., Pearce, C.R., Oelkers, E.H. (2012) An experimental study of the interaction of basaltic riverine particulate material and seawater. Geochim. Cosmochim. Acta 77, 108120.

Kheboian, C., Bauer, C.F. (1987) Accuracy of selective sequential extraction procedures for metal speciation in model aquatic sediments. Anal. Chem. 59, 1417-1423.

Klevenz, V., Vance, D., Schmidt, D.N., Mezger, K. (2008) Neodymium isotopes in benthic foraminifera: Core-top systematics and a down-core record from the Neogene south Atlantic. Earth Planet. Sci. Lett. 265, 571-587.

Kolla, V., Henderson, L., Biscaye, P.E. (1976) Clay mineralogy and sedimentation in the western Indian Ocean. Deep-Sea Research 23, 949-961.

Kuhn, T., Bau, M., Blum, N., Halbach, P. (1998) Origin of negative Ce anomalies in mixed hydrothermal-hydrogenetic Fe-Mn crusts from the Central Indian Ridge. Earth Planet. Sci. Lett. 163, 207-220.

Lacan, F., Jeandel, C. (2001) Tracing Papua New Guinea imprint on the central Equatorial Pacific Ocean using neodymium isotopic compositions and Rare Earth Element patterns. Earth Planet. Sci. Lett. 186, 497-512.

Lacan, F., Jeandel, C. (2005) Neodymium isotopes as a new tool for quantifying exchange fluxes at the continent-ocean interface. Earth Planet. Sci. Lett. 232, 245-257.

Luce, R.W., Bartlett, R.W., Parks, G.A. (1972) Dissolution kinetics of magnesium silicates. Geochim. Cosmochim. Acta 36, 35-50.

Martin, E.E., Blair, S.W., Kamenov, G.D., Scher, H.D., Bourbon, E., Basak, C., Newkirk, D.N. (2010) Extraction of Nd isotopes from bulk deep sea sediments for paleoceanographic studies on Cenozoic time scales. Chemical Geology 269, 414-431.

Martin, E.E., Haley, B.A. (2000) Fossil fish teeth as proxies for seawater $\mathrm{Sr}$ and $\mathrm{Nd}$ isotopes. Geochim. Cosmochim. Acta 64, 835-847.

McCave, I.N. (2001) RRS Charles Darwin cruise 129 report. Department of Earth Science, University of Cambridge, $U K$.

McLennan, S.M. (1989) Rare earth elements in sedimentary rocks - influence of provenance and sedimentary processes. Rev. Miner. 21, 169-200.

Mendez, J., Guieu, C., Adkins, J. (2010) Atmospheric input of manganese and iron to the ocean: seawater dissolution experiments with Saharan and North American dusts. Mar. Chem. 120, 34-43.

Moller, P., Giese, U. (1997) Determination of easily accessible metal fractions in rocks by batch leaching with acid cation-exchange resin. Chemical Geology 137, 41-55.

O'Nions, R.K., Carter, S.R., Cohen, R.S., Evensen, N.M., Hamilton, P.J. (1978) Pb, Nd and $\mathrm{Sr}$ isotopes in oceanic ferromanganese deposits and ocean floor basalts. Nature 273, 435 438.

O'Nions, R.K., Frank, M., von Blanckenburg, F., Ling, H.F. (1998) Secular variation of Nd and $\mathrm{Pb}$ isotopes in ferromanganese crusts from the Atlantic, Indian and Pacific Oceans. Earth Planet. Sci. Lett. 155, 15-28.

Oelkers, E.H., Gislason, S.R., Eiriksdottir, E.S., Jones, M., Pearce, C.R., Jeandel, C. (2011) The role of riverine particulate material on the global cycles of the elements. Appl. Geochem. 26, S365-S369. 
Pahnke, K., Goldstein, S.L., Hemming, S.R. (2008) Abrupt changes in Antarctic Intermediate Water circulation over the past 25,000 years. Nat. Geosci. 1, 870-874.

Palmer, M.R. (1985) Rare earth elements in foraminifera tests. Earth Planet. Sci. Lett. 73, 285-298.

Palmer, M.R., Elderfield, H. (1985) Variations in the Nd isotopic composition of foraminifera from Atlantic Ocean sediments. Earth Planet. Sci. Lett. 73, 299-305.

Palmer, M.R., Elderfield, H. (1986) Rare earth elements and neodymium isotopes in ferromanganese oxide coatings of Cenozoic foraminifera from the Atlantic Ocean. Geochim. Cosmochim. Acta 50, 409-417.

Pena, L.D., Cacho, I., Calvo, E., Pelejero, C., Eggins, S., Sadekov, A. (2008) Characterization of contaminant phases in foraminifera carbonates by electron microprobe mapping. Geochem. Geophys. Geosyst. 9, doi: 10.1029/2008gc002018.

Peucker-Ehrenbrink, B., Miller, M.W., Arsouze, T., Jeandel, C. (2010) Continental bedrock and riverine fluxes of strontium and neodymium isotopes to the oceans. Geochem. Geophys. Geosyst. 11, doi: 10.1029/2009gc002869.

Piepgras, D.J., Wasserburg, G.J., Dasch, E.J. (1979) The isotopic composition of Nd in different ocean masses. Earth Planet. Sci. Lett. 45, 223-236.

Piotrowski, A.M., Goldstein, S.L., Hemming, S.R., Fairbanks, R.G. (2004) Intensification and variability of ocean thermohaline circulation through the last deglaciation. Earth Planet. Sci. Lett. 225, 205-220.

Piotrowski, A.M., Galy, A., Nicholl, J.A.L., Roberts, N.L., Wilson, D.J., Clegg, J.A., Yu, J. (2012) Reconstructing deglacial North and South Atlantic deep water sourcing using foraminiferal Nd isotopes. Earth Planet. Sci. Lett. 357-358, 289-297.

Reimers, C.E., Ruttenberg, K.C., Canfield, D.E., Christiansen, M.B., Martin, J.B. (1996) Porewater $\mathrm{pH}$ and authigenic phases formed in the uppermost sediments of the Santa Barbara Basin. Geochim. Cosmochim. Acta 60, 4037-4057.

Rempfer, J., Stocker, T.F., Joos, F., Dutay, J.C., Siddall, M. (2011) Modelling Nd-isotopes with a coarse resolution ocean circulation model: Sensitivities to model parameters and source/sink distributions. Geochim. Cosmochim. Acta 75, 5927-5950.

Rendell, P.S., Batley, G.E. (1980) Adsorption as a control of metal concentrations in sediment extracts. Environ. Sci. Technol. 14, 314-318.

Roberts, N.L. (2012) PhD Thesis: Investigating North Atlantic ocean circulation using radiogenic isotopes, Department of Earth Sciences. University of Cambridge.

Roberts, N.L., Piotrowski, A.M., Elderfield, H., Eglinton, T., Lomas, M.W. (2012) Rare earth element association with foraminifera. Geochim. Cosmochim. Acta 94, 57-71.

Roberts, N.L., Piotrowski, A.M., McManus, J.F., Keigwin, L.D. (2010) Synchronous deglacial overturning and water mass source changes. Science 327, 75-78.

Rutberg, R.L., Hemming, S.R., Goldstein, S.L. (2000) Reduced North Atlantic Deep Water flux to the glacial Southern Ocean inferred from neodymium isotope ratios. Nature $\mathbf{4 0 5}$, 935-938.

Sholkovitz, E.R. (1989) Artifacts associated with the chemical leaching of sediments for rare-earth elements. Chemical Geology 77, 47-51. 
Siddall, M., Khatiwala, S., van de Flierdt, T., Jones, K., Goldstein, S.L., Hemming, S., Anderson, R.F. (2008) Towards explaining the Nd paradox using reversible scavenging in an ocean general circulation model. Earth Planet. Sci. Lett. 274, 448-461.

Staudigel, H., Doyle, P., Zindler, A. (1985) Sr and Nd isotope systematics in fish teeth. Earth Planet. Sci. Lett. 76, 45-56.

Stumpf, R., Frank, M., Schonfeld, J., Haley, B.A. (2010) Late Quaternary variability of Mediterranean Outflow Water from radiogenic $\mathrm{Nd}$ and $\mathrm{Pb}$ isotopes. Quat. Sci. Rev. 29, 2462-2472.

Sverdrup, H., Warfvinge, P. (1995) Estimating field weathering rates using laboratory kinetics. Rev. Miner. 31, 485-541.

Tachikawa, K., Athias, V., Jeandel, C. (2003) Neodymium budget in the modern ocean and paleo-oceanographic implications. J. Geophys. Res.-Oceans 108, doi:10.1029/1999JC000285.

Tachikawa, K., Jeandel, C., Roy-Barman, M. (1999) A new approach to the Nd residence time in the ocean: the role of atmospheric inputs. Earth Planet. Sci. Lett. 170, 433-446.

Tachikawa, K., Roy-Barman, M., Michard, A., Thouron, D., Yeghicheyan, D., Jeandel, C. (2004) Neodymium isotopes in the Mediterranean Sea: Comparison between seawater and sediment signals. Geochim. Cosmochim. Acta 68, 3095-3106.

Tachikawa, K., Toyofuku, T., Basile-Doelsch, I., Delhaye, T. (2013) Microscale neodymium distribution in sedimentary planktonic foraminiferal tests and associated mineral phases. Geochim. Cosmochim. Acta 100, 11-23.

Tanaka, T., Togashi, S., Kamioka, H., Amakawa, H., Kagami, H., Hamamoto, T., Yuhara, M., Orihashi, Y., Yoneda, S., Shimizu, H., Kunimaru, T., Takahashi, K., Yanagi, T., Nakano, T., Fujimaki, H., Shinjo, R., Asahara, Y., Tanimizu, M., Dragusanu, C. (2000) JNdi-1: a neodymium isotopic reference in consistency with LaJolla neodymium. Chemical Geology 168, 279-281.

Tessier, A., Campbell, P.G.C., Bisson, M. (1979) Sequential extraction procedure for the speciation of particulate trace metals. Anal. Chem. 51, 844-851.

Tipping, E., Hetherington, N.B., Hilton, J., Thompson, D.W., Bowles, E., Hamiltontaylor, J. (1985) Artifacts in the use of selective chemical extraction to determine distributions of metals between oxides of manganese and iron. Anal. Chem. 57, 1944-1946.

Vance, D., Scrivner, A.E., Beney, P., Staubwasser, M., Henderson, G.M., Slowey, N.C. (2004) The use of foraminifera as a record of the past neodymium isotope composition of seawater. Paleoceanography 19, doi:10.1029/2003PA000957.

White, W.M., Cheatham, M.M., Duncan, R.A. (1990) Isotope geochemistry of leg 115 basalts and inferences on the history of the Reunion mantle plume. Proceedings of the Ocean Drilling Program Scientific Results 115, 53-61.

Wilson, D.J., Piotrowski, A.M., Galy, A., McCave, I.N. (2012) A boundary exchange influence on deglacial neodymium isotope records from the deep western Indian Ocean. Earth Planet. Sci. Lett. 341-344, 35-47. 


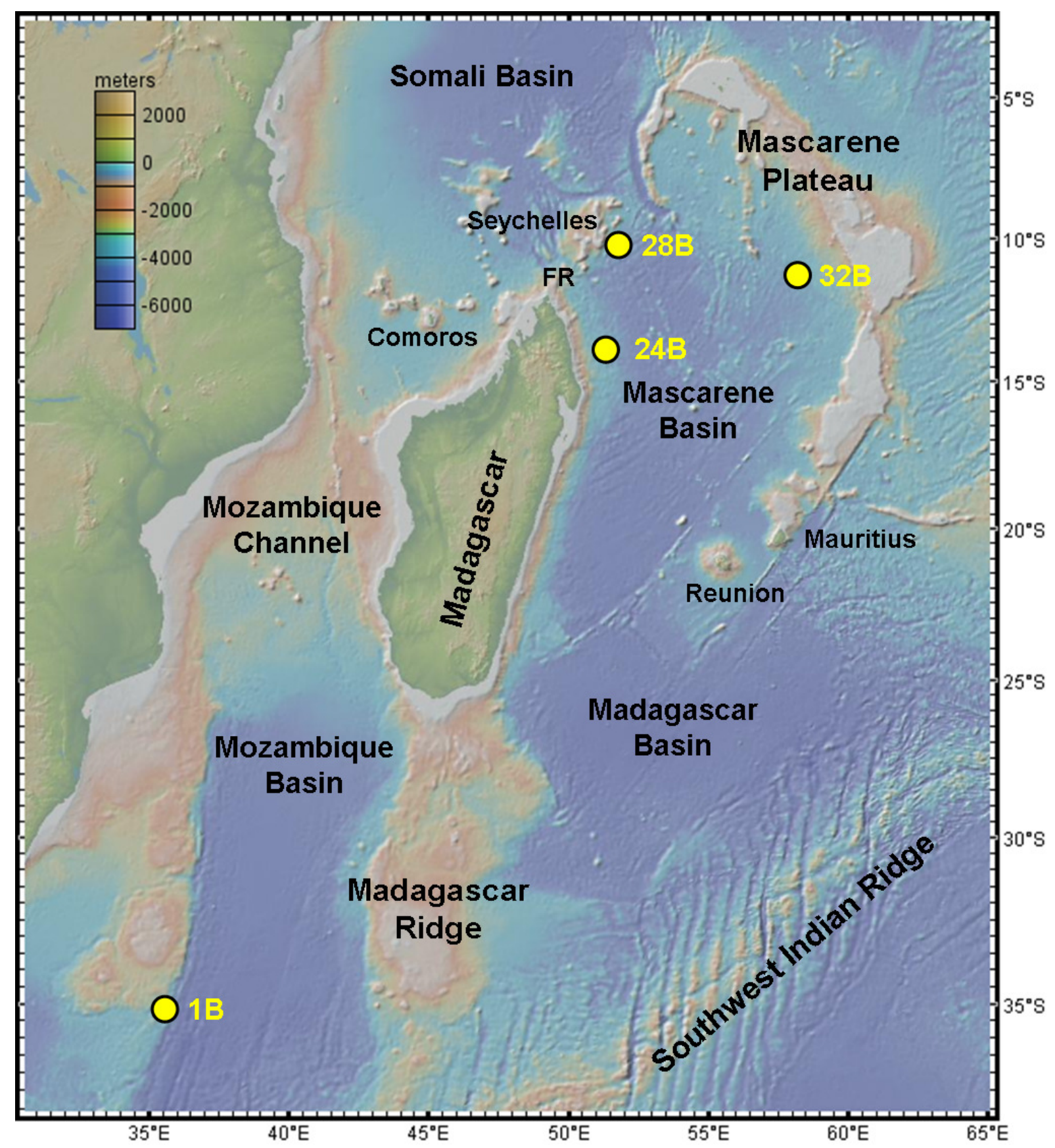

Fig. 1. Location map for the WIND sediment core sites (yellow circles and labels) in the Mascarene Basin (WIND 24B, 28B, 32B) and Mozambique Basin (WIND 1B). FR = Farquhar Ridge. Base map from GeoMapApp. 


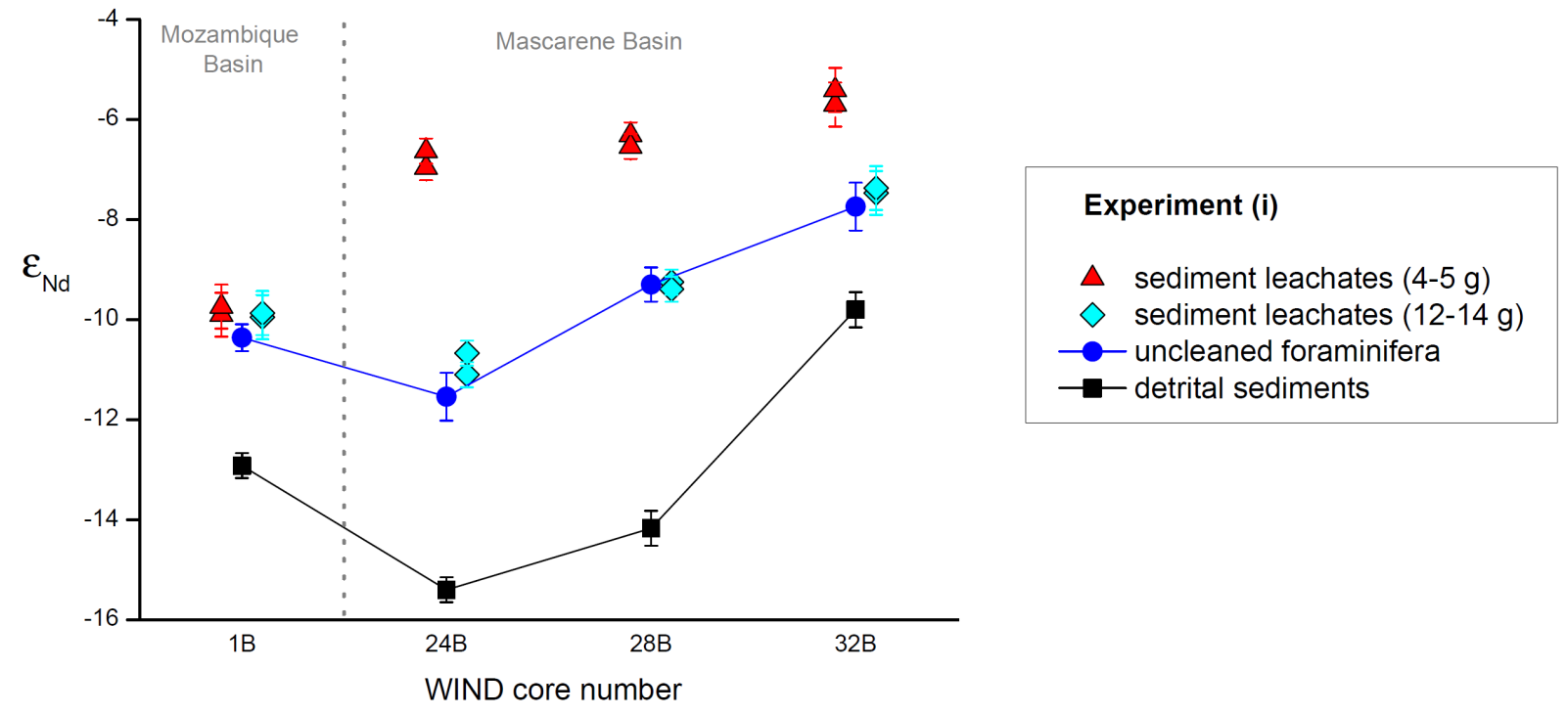

Fig. 2. Results of leaching experiment (i) on WIND 1B, 24B, 28B and 32B, illustrating the effect of sample size on leachate $\varepsilon_{\mathrm{Nd}}$ compositions. The $\varepsilon_{\mathrm{Nd}}$ compositions of uncleaned foraminifera and detrital sediment in each core are shown for comparison (data from Wilson et al., 2012 and this study) and connected by lines which define a region in which the leachate data would be expected to plot for admixture between the authigenic and detrital components. Note that the leachate data from each core is offset slightly along the $\mathrm{x}$ axis for clarity. 

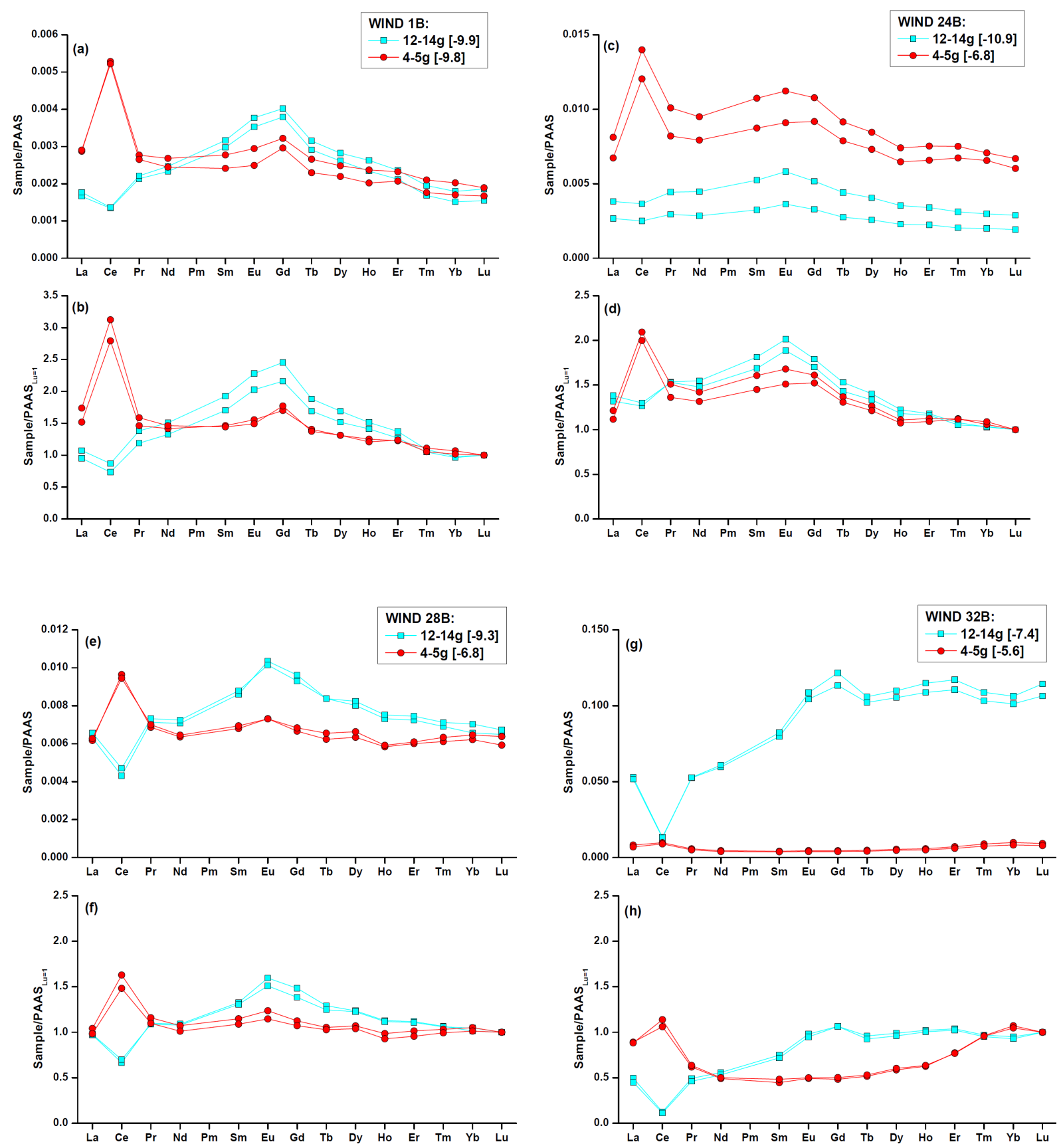

Fig. 3. REE patterns from leaching experiment (i) investigating sample sizes for $(a, b)$ WIND 1B, (c,d) WIND 24B, (e,f) WIND 28B, and (g,h) WIND 32B. In each case these are plotted with $(\mathrm{a}, \mathrm{c}, \mathrm{e}, \mathrm{g})$ normalisation to PAAS, and $(\mathrm{b}, \mathrm{d}, \mathrm{f}, \mathrm{h})$ normalisation to PAAS and to [Lu] $=1$. Note the use of different y axes scales between plots, in particular for panel (g) where the 12$14 \mathrm{~g}$ samples from WIND 32B have an order of magnitude higher REE concentrations which we attribute to incomplete decarbonation (cf. Fig. 5a). Numbers in square brackets in the keys to panels $(\mathrm{a}, \mathrm{c}, \mathrm{e}, \mathrm{g})$ are the average $\varepsilon_{\mathrm{Nd}}$ values for each sample size. 
(a)

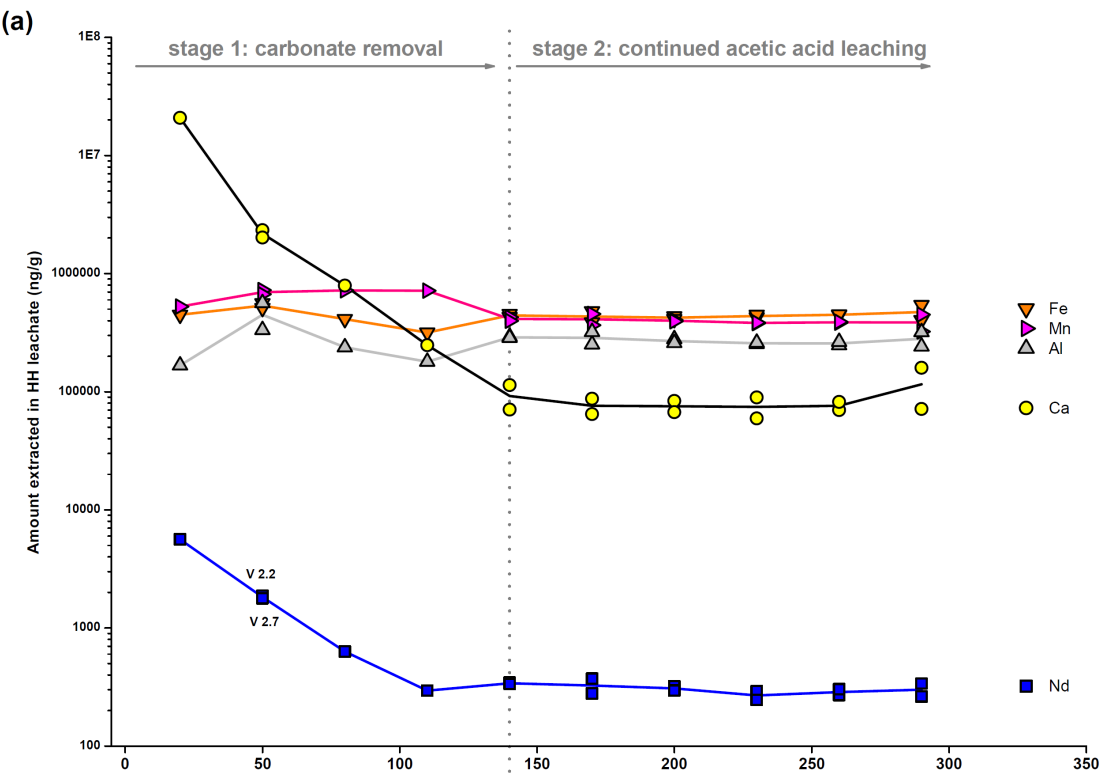

(b)

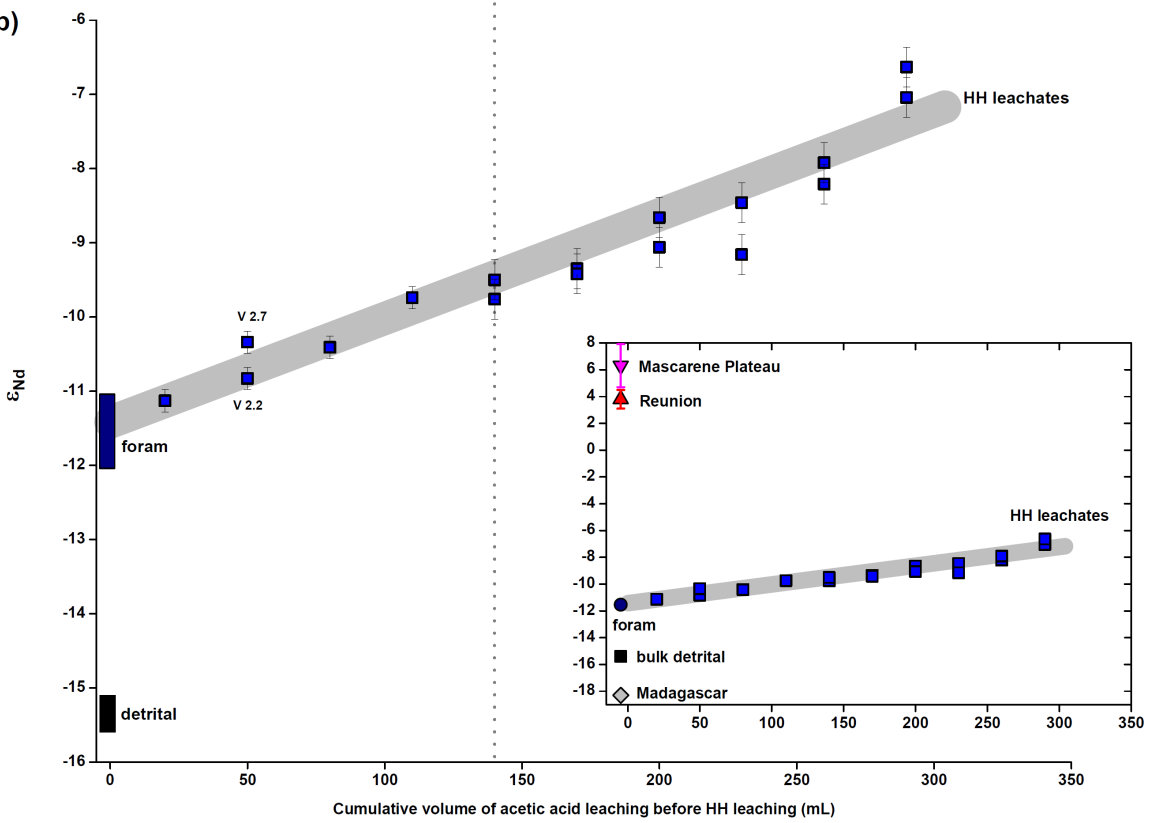

Fig. 4. Results of leaching experiment (ii) on WIND 24B, illustrating the effect of the acetic acid leaching history of samples on the subsequent $\mathrm{HH}$ leaching. Panel (a) shows elemental concentrations on a logarithmic scale and panel (b) shows $\varepsilon_{\mathrm{Nd}}$ compositions of the $\mathrm{HH}$ leachates. The dotted line divides the leaching into stage 1 (carbonate removal) and stage 2 (continued acetic acid leaching) on the basis of $\mathrm{Ca}$ concentrations. In panel (b) the $\varepsilon_{\mathrm{Nd}}$ compositions of uncleaned foraminifera and detrital sediment from WIND 24B (Wilson et al., 2012) are also shown and the grey band depicts the approximate evolution of leachate $\varepsilon_{\mathrm{Nd}}$ values. We also note the good agreement for six full procedural replicates that are also shown. Labels refer to samples V2.2 (acetic acid leached 2 times over 2 days) and V2.7 (acetic acid leached 2 times over 7 days). The inset to panel (b) reproduces the data using a wider range on the y axis in order to make comparison to the $\varepsilon_{\mathrm{Nd}}$ compositions of volcanic rocks from the Mascarene Plateau (White et al., 1990) and Reunion (Bosch et al., 2008) and the Madagascan detrital sediment endmember (Wilson et al., 2012), which are used in our mass balance calculations (Section 4.2.2). 
(a)

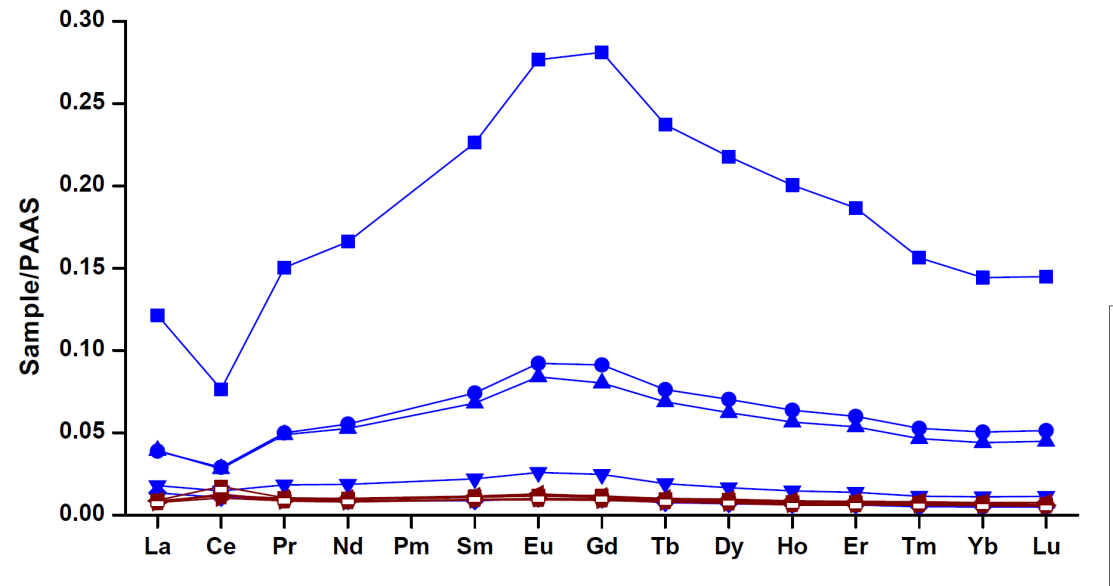

(b)

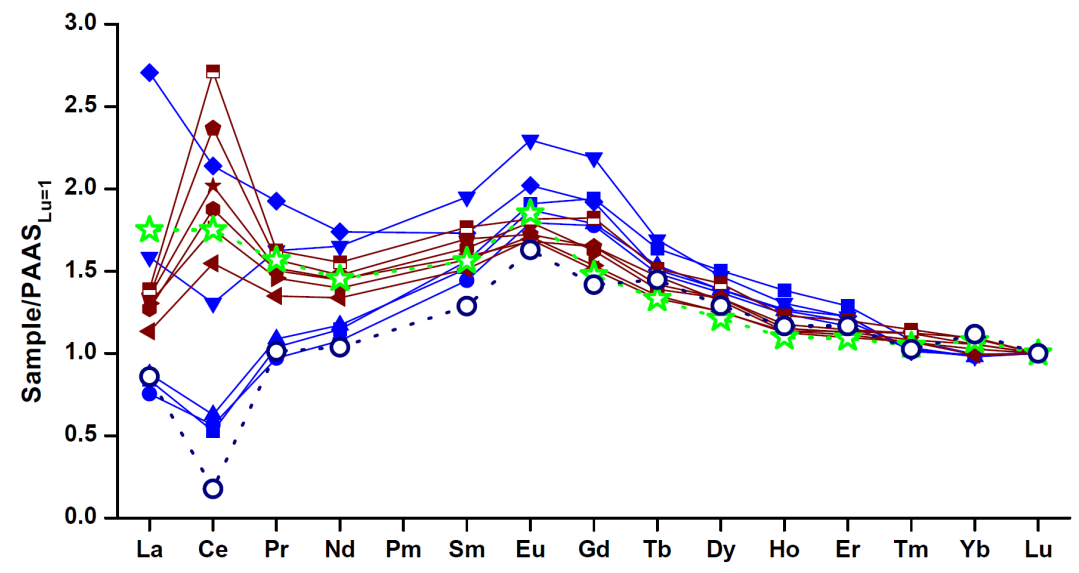

Experiment (ii)

Stage 1

$\rightarrow-V 1.1[-11.1]$

$-V 2.2[-10.8]$

$-\mathrm{V} 2.7[-10.3]$

$\rightarrow-V 3.3[-10.4]$

$\longrightarrow$ V4.7 [-9.7]

Stage 2

4 V5.13a [-9.8]

$\rightarrow-V 6.14 a[-9.4]$

$\rightarrow-V 7.16 a[-8.7]$

\# V8.20a [-8.5]

$\rightarrow$ V9.22a [-8.2]

$\rightarrow$ V10.27a $[-7.0]$

- $\bigcirc$ - uncleaned foraminifera

- detrital sediment

Fig. 5. REE patterns from WIND 24B leaching experiment (ii), plotted (a) with normalisation to PAAS, and (b) with normalisation to PAAS and to $[\mathrm{Lu}]=1$. Labels in the key are sample codes, with $\varepsilon_{\mathrm{Nd}}$ values in square brackets. Also shown in (b) are the REE patterns of uncleaned sedimentary foraminifera (Roberts, 2012) and detrital sediment (this study), both sampled from the WIND 24B coretop. 
(a)

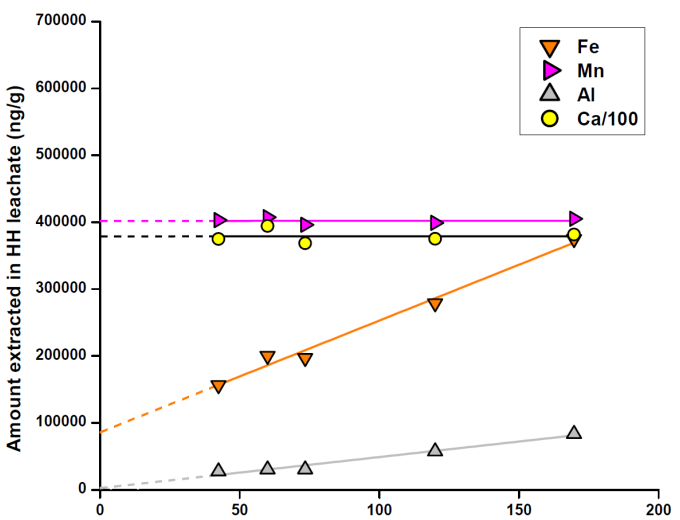

(b)

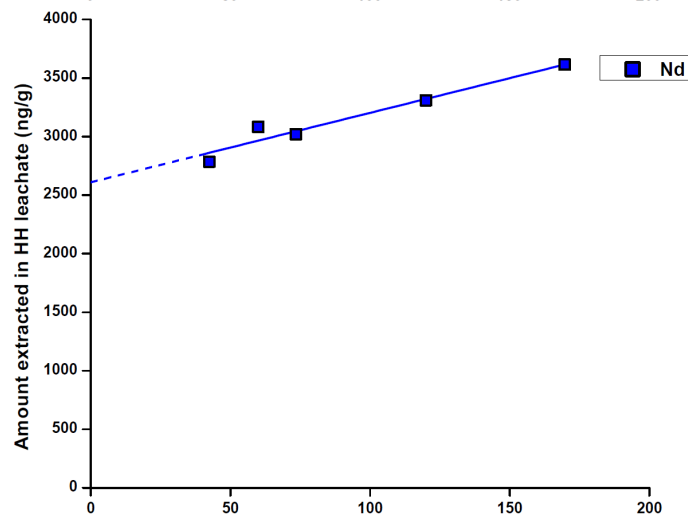

(c)

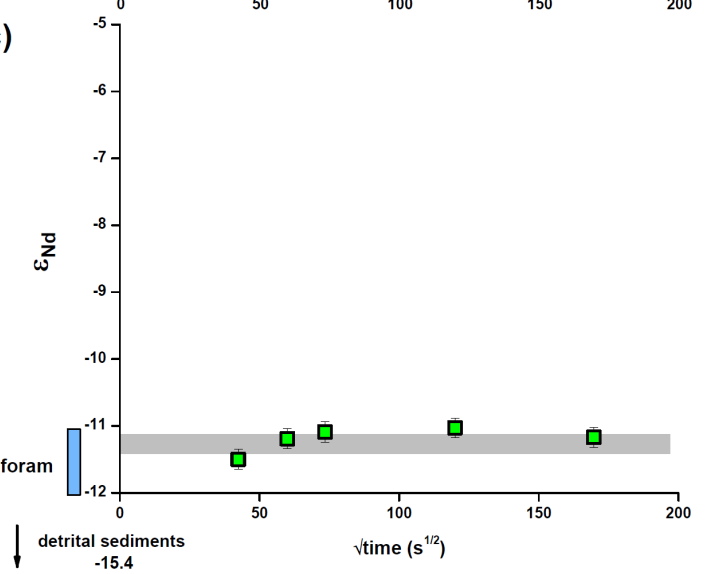

(d)

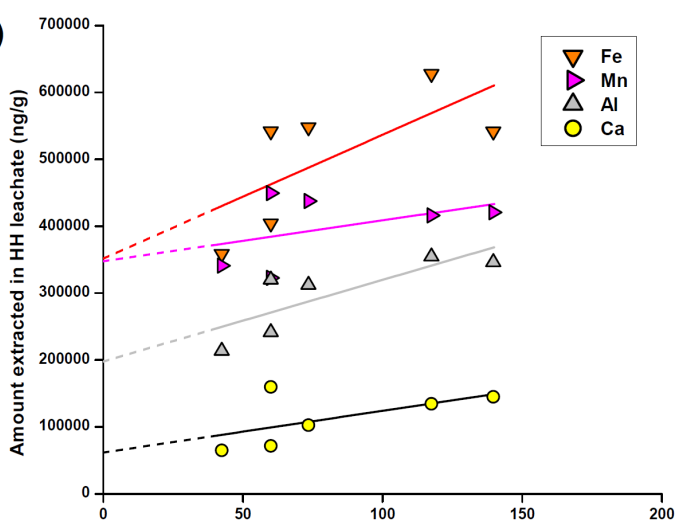

(e)

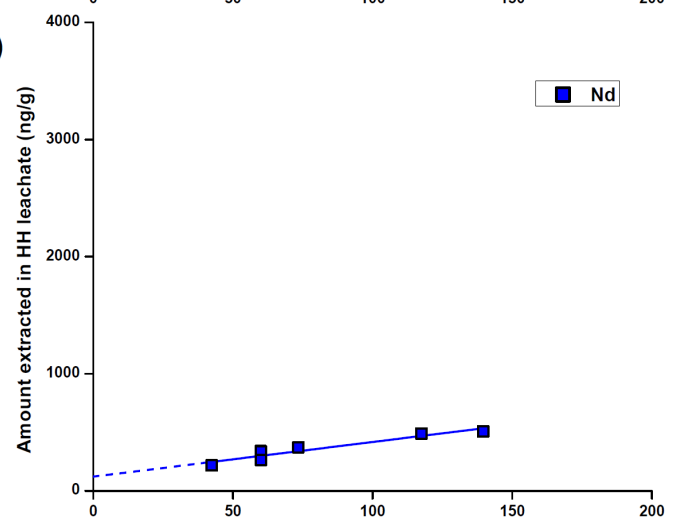

(f)

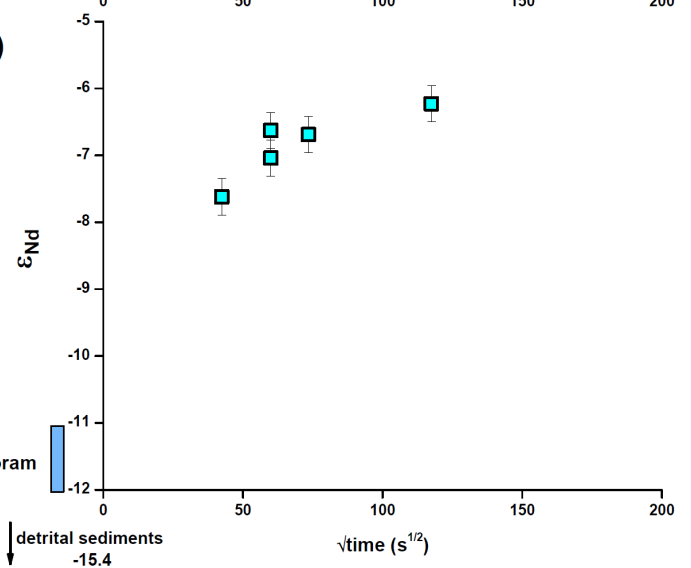

Fig. 6. Results of leaching experiments (iii) and (iv) on WIND 24B, illustrating the effect of the $\mathrm{HH}$ leaching time (plotted as $\sqrt{\text { time}}$ ), with either no prior acetic acid leaching (panels a-c) or after extended acetic acid leaching (panels d-f). For each experiment, the upper two panels show elemental concentrations and the lower panel shows $\varepsilon_{\mathrm{Nd}}$ compositions. The same y axis scales are used for both experiments, but note that $\mathrm{Ca}$ is plotted as $\mathrm{Ca} / 100$ in experiment (iii) (panel a). Elemental concentrations are fitted with straight lines which represent the kinetic control on the reaction. Since the true evolution between 0 and 30 minutes is unknown, the lines are extended as dashed lines between 0 and 30 minutes to demonstrate the predicted behaviour according to a kinetic control. The y intercept therefore represents the amount of an element leached quickly under a different control, but how quickly this occurs (within that 30 minute period) is unconstrained. Also shown in panels (c) and (f) are the $\varepsilon_{\mathrm{Nd}}$ compositions of uncleaned foraminifera and detrital sediment in WIND 24B (from Wilson et al., 2012). In experiment (iii), all the leachates have $\varepsilon_{\mathrm{Nd}}$ compositions within error of the value shown by the grey bar in panel (c), whereas there is temporal variability in leachate $\varepsilon_{\mathrm{Nd}}$ compositions in experiment (iv). 

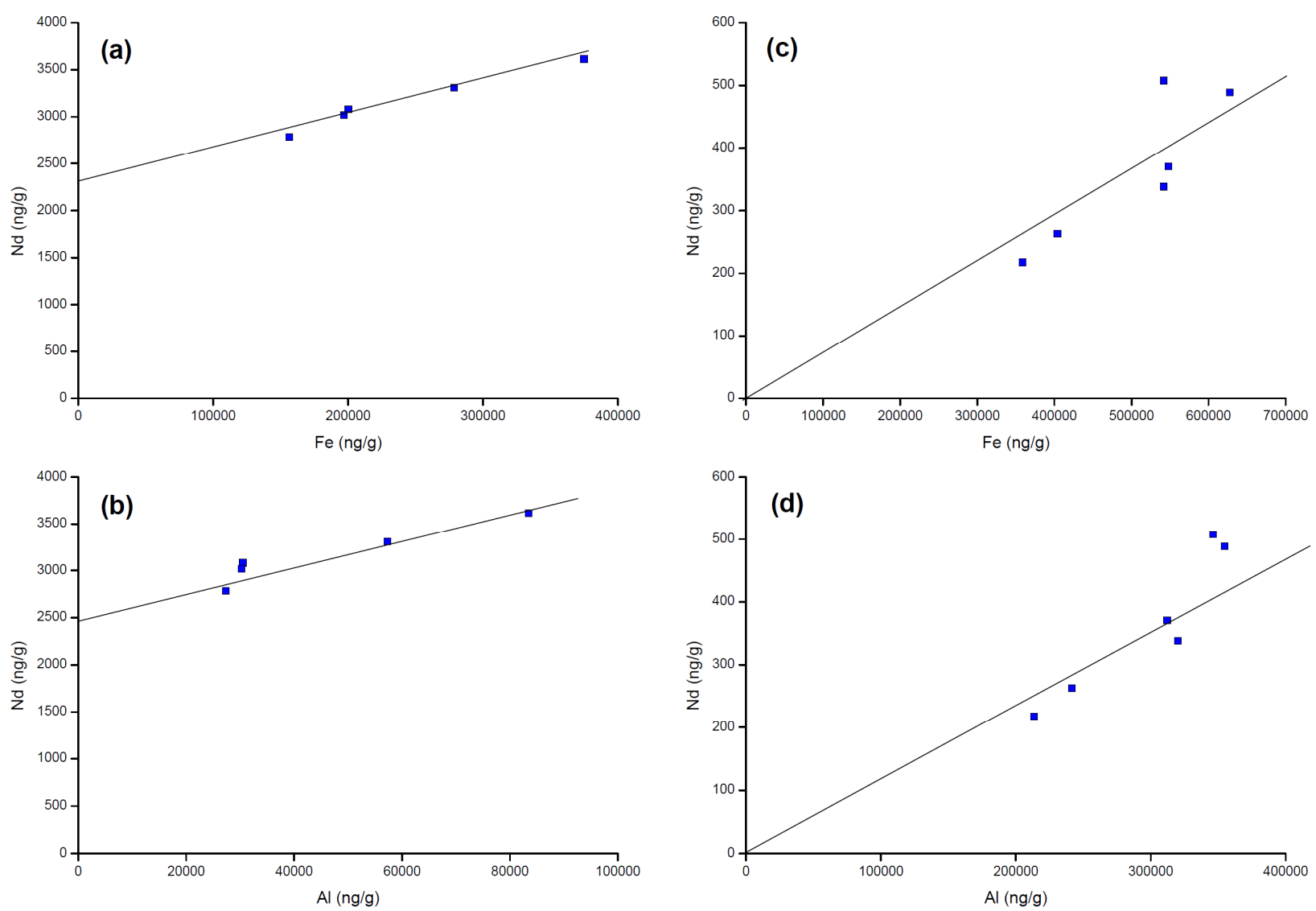

Fig. 7. Crossplots of $\mathrm{Nd}$ versus $\mathrm{Fe}$ and $\mathrm{Nd}$ versus $\mathrm{Al}$ in $\mathrm{HH}$ leachates from experiments (iii) (panels a,b) and (iv) (panels c,d). Note the differing axis scales between experiments (iii) and (iv). The lines are indicative of the trends present, rather than mathematical fits to the data, and for experiment (iv) are fitted through the origin. 

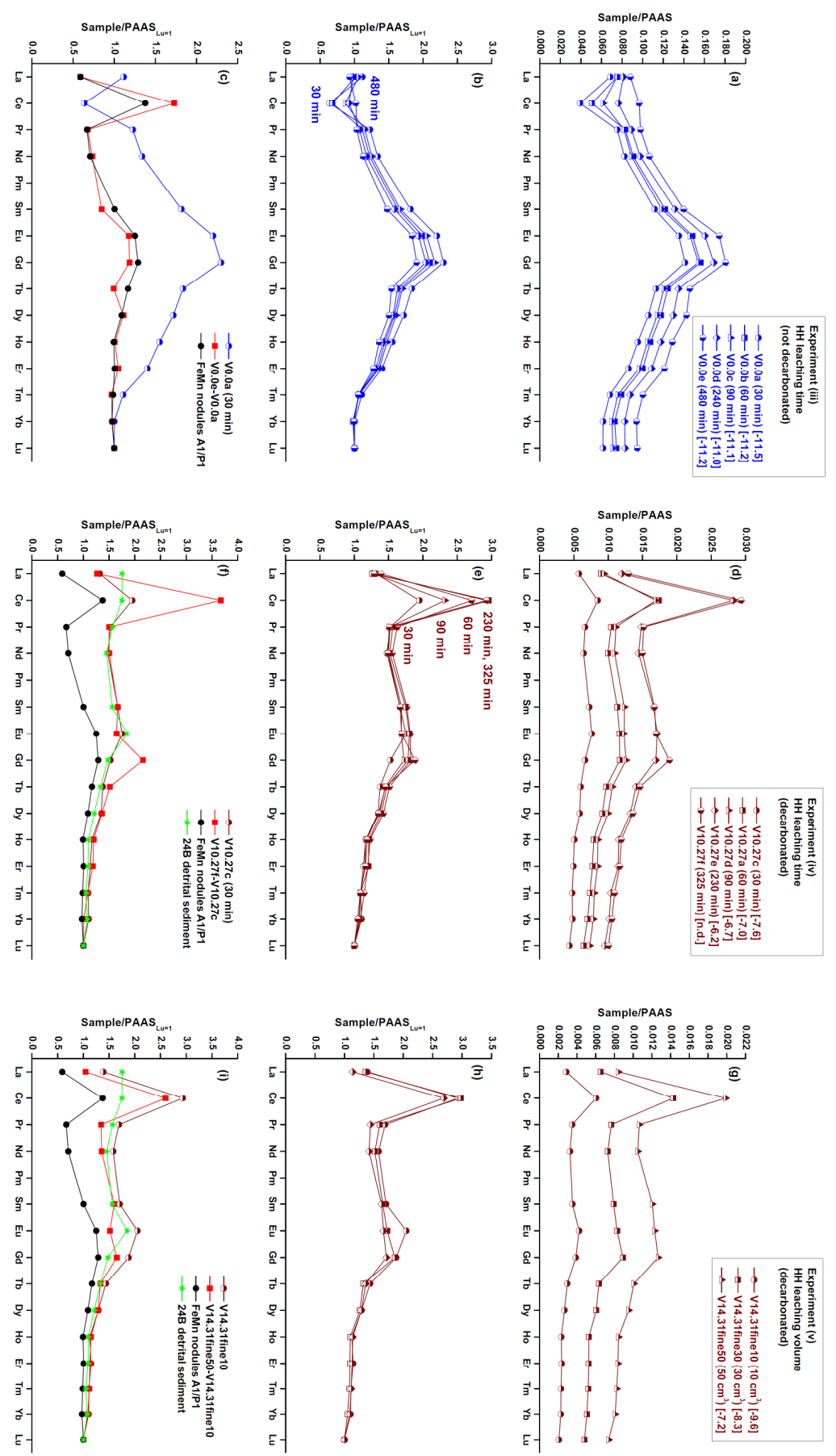

Fig. 8. REE patterns from WIND 24B leaching experiments (iii), (iv) and (v). Panels (a,b,c) show the effect of the HH leaching time on non-decarbonated samples. Panels (d,e,f) show the effect of the HH leaching time on decarbonated samples. Panels $(\mathrm{g}, \mathrm{h}, \mathrm{i})$ show the effect of the HH leaching volume on decarbonated samples. Upper panels (a,d,g) use normalisation to PAAS, and middle panels $(\mathrm{b}, \mathrm{e}, \mathrm{h})$ use normalisation to PAAS and to $[\mathrm{Lu}]=1$. Lower panels $(\mathrm{c}, \mathrm{f}, \mathrm{i})$ show REE patterns calculated from the differences between the longest and shortest leaching times $(\mathrm{c}, \mathrm{f})$ or the largest and smallest leaching volumes (i). A representative REE pattern for ferromanganese nodules (based on the average of USGS ferromanganese nodule standards A1 and P1; Kuhn et al., 1998) is shown in panels (c,f,i) and the REE pattern of detrital sediments in core WIND 24B is shown in panels (f,i). Selected HH leaching times are labelled on plots $(\mathrm{b}, \mathrm{e})$ alongside the Ce data. Numbers in square brackets in the keys to panels $(\mathrm{a}, \mathrm{d}, \mathrm{g})$ are leachate $\varepsilon_{\mathrm{Nd}}$ values. 
Experiment (v) - HH leaching volume (decarbonated)

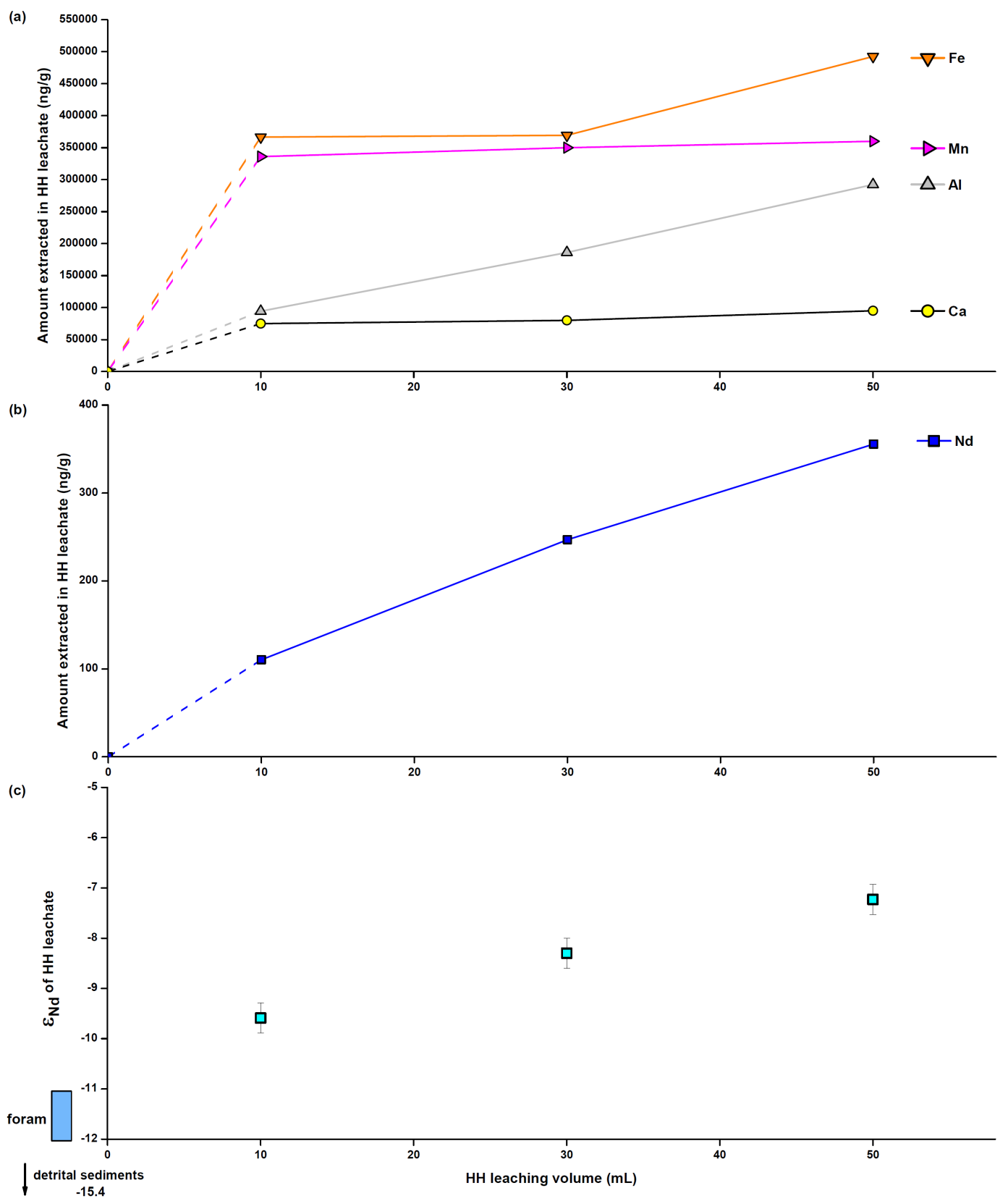

Fig. 9. Results of leaching experiment (v) on WIND 24B, illustrating the effect of the HH leaching volume, after extended acetic acid leaching. Panels (a) and (b) show elemental concentrations of the $\mathrm{HH}$ leachates on linear scales, with dashed lines from $0-10 \mathrm{~mL}$ to emphasise the uncertainty in the evolution over this volume range. Panel (c) shows $\varepsilon_{\mathrm{Nd}}$ compositions of the $\mathrm{HH}$ leachates compared to the $\varepsilon_{\mathrm{Nd}}$ compositions of uncleaned foraminifera and detrital sediment in WIND 24B (from Wilson et al., 2012). 


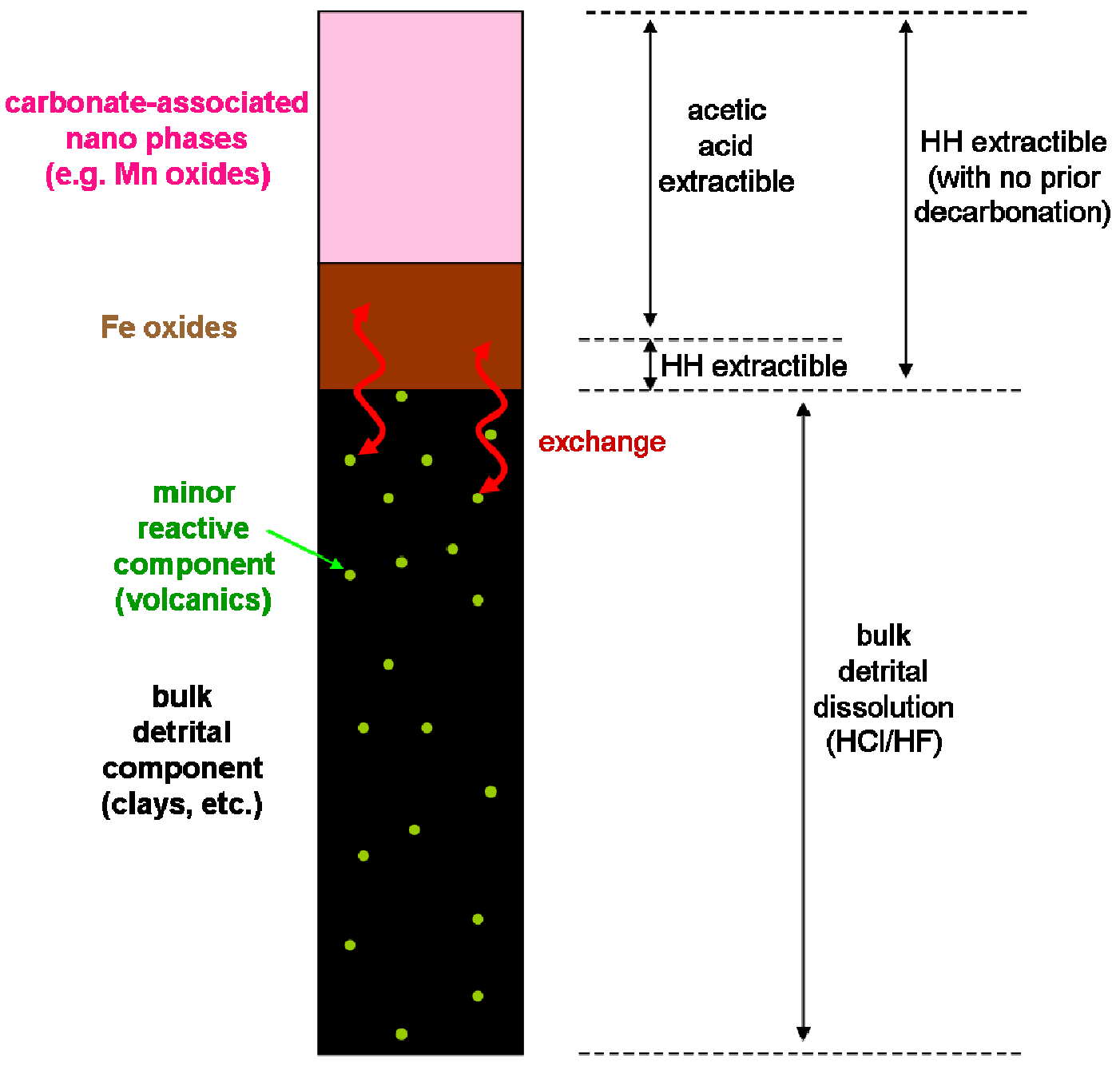

Fig. 10: A schematic Nd budget for deep sea sediment, represented as a sediment column. The components present are described on the left and their extraction by different reagents is shown on the right. The size of each component within the column represents its approximate contribution to the Nd budget based on WIND 24B leaching experiments, but this will differ from core to core. 
Table 1: Description of sediment samples from WIND box cores.

\begin{tabular}{|c|c|c|c|c|c|c|c|}
\hline Core & $\begin{array}{l}\text { Latitude } \\
\text { (deg S) }\end{array}$ & $\begin{array}{l}\text { Longitude } \\
\text { (deg E) }\end{array}$ & $\begin{array}{l}\text { Water depth } \\
\text { (m.b.s.l.) }\end{array}$ & $\begin{array}{l}\text { Sample depth } \\
\text { (cm) }\end{array}$ & 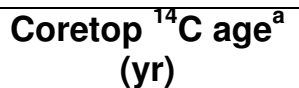 & $\begin{array}{c}\text { Carbonate content }^{\mathrm{b}} \\
(\%)\end{array}$ & $\begin{array}{c}\text { Clay mineralogy }^{\mathrm{c}} \\
\mathrm{S} / \mathrm{I} / \mathrm{K} / \mathrm{C}(\%)\end{array}$ \\
\hline WIND 1B & $35^{\circ} 07.31^{\prime}$ & $35^{\circ} 32.12^{\prime}$ & 4156 & $0-2$ & 1043 & 54 & $40 / 40 / 10 /<10$ \\
\hline WIND 24B & $13^{\circ} 04.45^{\prime}$ & $51^{\circ} 20.01^{\prime}$ & 4163 & $0-2$ & 4167 & 25 & $45 / 10 / 35 /<10$ \\
\hline WIND 28B & $10^{\circ} 09.33^{\prime}$ & $51^{\circ} 46.22^{\prime}$ & 4147 & $0-2$ & 5484 & 43 & $50 / 15 / 25 /<10$ \\
\hline WIND 32B & $11^{\circ} 14.19^{\prime}$ & $58^{\circ} 13.18^{\prime}$ & 4117 & $0-2$ & 4663 & 80 & $55 / 15 / 20 /<10$ \\
\hline
\end{tabular}

\section{Notes}

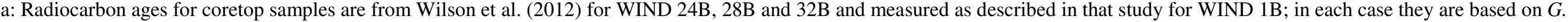
sacculifer and no reservoir age correction or calendar year calibration has been applied.

b: Carbonate contents for coretop samples are from Wilson et al. (2012) for WIND 24B, 28B and 32B and measured as described in that study for WIND 1B.

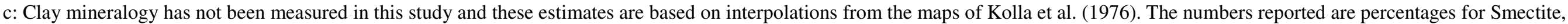

Illite, Kaolinite and Chlorite and are likely correct to within $\sim 10 \%$.

\section{Table 2: Summary of the experiments}

\begin{tabular}{|c|c|c|c|c|c|c|}
\hline Experiment & Testing & Samples & Wet weight & Acetic acid leaching volume & HH leaching time & HH leaching volume \\
\hline (i) & Sample size & 1B, 24B, 28B, 32B & varied $(12-14 \mathrm{~g}, 4-5 \mathrm{~g})$ & $440 \mathrm{~mL}$ & 60 mins & $30 \mathrm{~mL}$ \\
\hline (ii) & Acetic acid leaching volume & $24 B$ & $\sim 4.5 \mathrm{~g}$ & varied $(20 \mathrm{~mL}-290 \mathrm{~mL})$ & $60 \mathrm{mins}$ & $30 \mathrm{~mL}$ \\
\hline (iii) & $\mathrm{HH}$ leaching time, non-decarbonated & 24B & $\sim 4.5 \mathrm{~g}$ & none & varied (30 mins-480 mins) & $30 \mathrm{~mL}$ \\
\hline (iv) & HH leaching time, decarbonated & 24B & $\sim 4.5 \mathrm{~g}$ & $290 \mathrm{~mL}$ & varied (30 mins-325 mins) & $30 \mathrm{~mL}$ \\
\hline (v) & $\mathrm{HH}$ leaching volume, decarbonated & 24B & $\sim 4.5 \mathrm{~g}$ & $410 \mathrm{~mL}$ & 60 mins & varied $(10 \mathrm{~mL}-50 \mathrm{~mL})$ \\
\hline
\end{tabular}


Table 3: Experimental details and Nd isotope data

\begin{tabular}{|c|c|c|c|c|c|c|c|c|c|c|c|c|c|}
\hline Experiment & Core & Label & $\begin{array}{r}\text { Wet } \\
\text { pre-A (g) }\end{array}$ & $\begin{array}{l}\text { veight } \\
\text { post-A (g) }\end{array}$ & $\begin{array}{c}\mathbf{T}_{\text {vortex }} \\
\text { (minutes) }\end{array}$ & $\mathbf{N}_{\mathbf{A}}$ & $\begin{array}{c}T_{A} \\
\text { (days) }\end{array}$ & $\begin{array}{c}\mathrm{V}_{\mathrm{A}} \\
(\mathrm{mL})\end{array}$ & $\begin{array}{c}\mathrm{T}_{\mathrm{HH}} \\
\text { (minutes) }\end{array}$ & $\begin{array}{l}\mathrm{V}_{\mathrm{HH}} \\
(\mathrm{mL})\end{array}$ & $\varepsilon_{\mathrm{Nd}}$ & $2 \sigma$ & $\begin{array}{c}{[\mathrm{Nd}]} \\
(\mathrm{ng} / \mathrm{g})\end{array}$ \\
\hline (i) & 1B & $1 \mathrm{HL}$ & 13.20 & 5.86 & n.d. & 15 & 48 & 440 & 60 & 30 & -9.87 & 0.44 & 79 \\
\hline (i) & 1B & $1 \mathrm{~L}$ & 13.74 & 6.48 & n.d. & 15 & 48 & 440 & 60 & 30 & -9.95 & 0.44 & 84 \\
\hline (i) & 1B & $1 \mathrm{HS}$ & 3.87 & 2.20 & n.d. & 15 & 48 & 440 & 60 & 30 & -9.90 & 0.44 & 91 \\
\hline (i) & $1 B$ & $1 S$ & 4.10 & 2.24 & n.d. & 15 & 48 & 440 & 60 & 30 & -9.74 & 0.44 & 83 \\
\hline (i) & 24B & $24 \mathrm{HL}$ & 13.76 & 10.26 & n.d. & 15 & 24 & 440 & 60 & 30 & -10.67 & 0.25 & 152 \\
\hline (i) & 24B & $24 \mathrm{~L}$ & 13.28 & 10.34 & n.d. & 15 & 24 & 440 & 60 & 30 & -11.10 & 0.25 & 97 \\
\hline (i) & 24B & $24 \mathrm{HS}$ & 4.38 & 3.70 & n.d. & 15 & 24 & 440 & 60 & 30 & -6.96 & 0.25 & 322 \\
\hline (i) & 24B & $24 \mathrm{~S}$ & 4.11 & 3.55 & n.d. & 15 & 24 & 440 & 60 & 30 & -6.63 & 0.25 & 269 \\
\hline (i) & 28B & $28 \mathrm{HL}$ & 12.00 & 7.52 & n.d. & 15 & 24 & 440 & 60 & 30 & -9.39 & 0.25 & 240 \\
\hline (i) & 28B & $28 \mathrm{~L}$ & 11.51 & 7.13 & n.d. & 15 & 24 & 440 & 60 & 30 & -9.25 & 0.25 & 246 \\
\hline (i) & $28 B$ & $28 \mathrm{HS}$ & 4.37 & 3.57 & n.d. & 15 & 24 & 440 & 60 & 30 & -6.31 & 0.25 & 215 \\
\hline (i) & $28 B$ & $28 \mathrm{~S}$ & 4.58 & 3.66 & n.d. & 15 & 24 & 440 & 60 & 30 & -6.54 & 0.25 & 219 \\
\hline (i) & $32 B$ & $32 \mathrm{HL}$ & 13.24 & 4.54 & n.d. & 15 & 48 & 440 & 60 & 30 & -7.37 & 0.44 & 2018 \\
\hline (i) & 32B & $32 \mathrm{~L}$ & 13.49 & 4.58 & n.d. & 15 & 48 & 440 & 60 & 30 & -7.47 & 0.44 & 2063 \\
\hline (i) & 32B & $32 \mathrm{HS}$ & 4.14 & 1.77 & n.d. & 15 & 48 & 440 & 60 & 30 & -5.70 & 0.44 & 153 \\
\hline (i) & 32B & $32 \mathrm{~S}$ & 3.90 & 1.81 & n.d. & 15 & 48 & 440 & 60 & 30 & -5.41 & 0.44 & 133 \\
\hline (ii) & 24B & V1.1 & 4.56 & 4.86 & 5.7 & 1 & 1 & 20 & 60 & 30 & -11.13 & 0.15 & 5628 \\
\hline (ii) & 24B & V2.2 & 4.54 & 4.66 & 7.8 & 2 & 2 & 50 & 60 & 30 & -10.83 & 0.15 & 1874 \\
\hline (ii) & 24B & V2.7 & 4.49 & 4.34 & 7.8 & 2 & 7 & 50 & 60 & 30 & -10.34 & 0.15 & 1782 \\
\hline (ii) & 24B & V3.3 & 4.50 & 4.57 & 9.8 & 3 & 3 & 80 & 60 & 30 & -10.41 & 0.15 & 631 \\
\hline (ii) & 24B & V4.7 & 4.51 & 4.57 & 11.9 & 4 & 7 & 110 & 60 & 30 & -9.74 & 0.15 & 295 \\
\hline (ii) & 24B & V5.13a & 4.49 & 4.10 & 14.4 & 5 & 13 & 140 & 60 & 30 & -9.76 & 0.27 & 345 \\
\hline (ii) & 24B & V5.13b & 4.53 & 4.09 & 14.4 & 5 & 13 & 140 & 60 & 30 & -9.50 & 0.27 & 336 \\
\hline (ii) & 24B & V6.14a & 4.56 & 4.04 & 16.5 & 6 & 14 & 170 & 60 & 30 & -9.35 & 0.27 & 279 \\
\hline (ii) & 24B & V6.14b & 4.54 & 4.01 & 16.5 & 6 & 14 & 170 & 60 & 30 & -9.42 & 0.27 & 372 \\
\hline (ii) & 24B & V7.16a & 4.49 & 4.08 & 18.6 & 7 & 16 & 200 & 60 & 30 & -8.66 & 0.27 & 320 \\
\hline (ii) & 24B & V7.16b & 4.47 & 4.08 & 18.6 & 7 & 16 & 200 & 60 & 30 & -9.06 & 0.27 & 296 \\
\hline (ii) & 24B & V8.20a & 4.51 & 4.03 & 35.7 & 8 & 20 & 230 & 60 & 30 & -8.46 & 0.27 & 292 \\
\hline (ii) & 24B & V8.20b & 4.49 & 4.03 & 20.7 & 8 & 20 & 230 & 60 & 30 & -9.16 & 0.27 & 246 \\
\hline (ii) & 24B & V9.22a & 4.47 & 4.05 & 37.8 & 9 & 22 & 260 & 60 & 30 & -8.21 & 0.27 & 270 \\
\hline (ii) & 24B & V9.22b & 4.34 & 3.88 & 22.8 & 9 & 22 & 260 & 60 & 30 & -7.92 & 0.27 & 303 \\
\hline
\end{tabular}




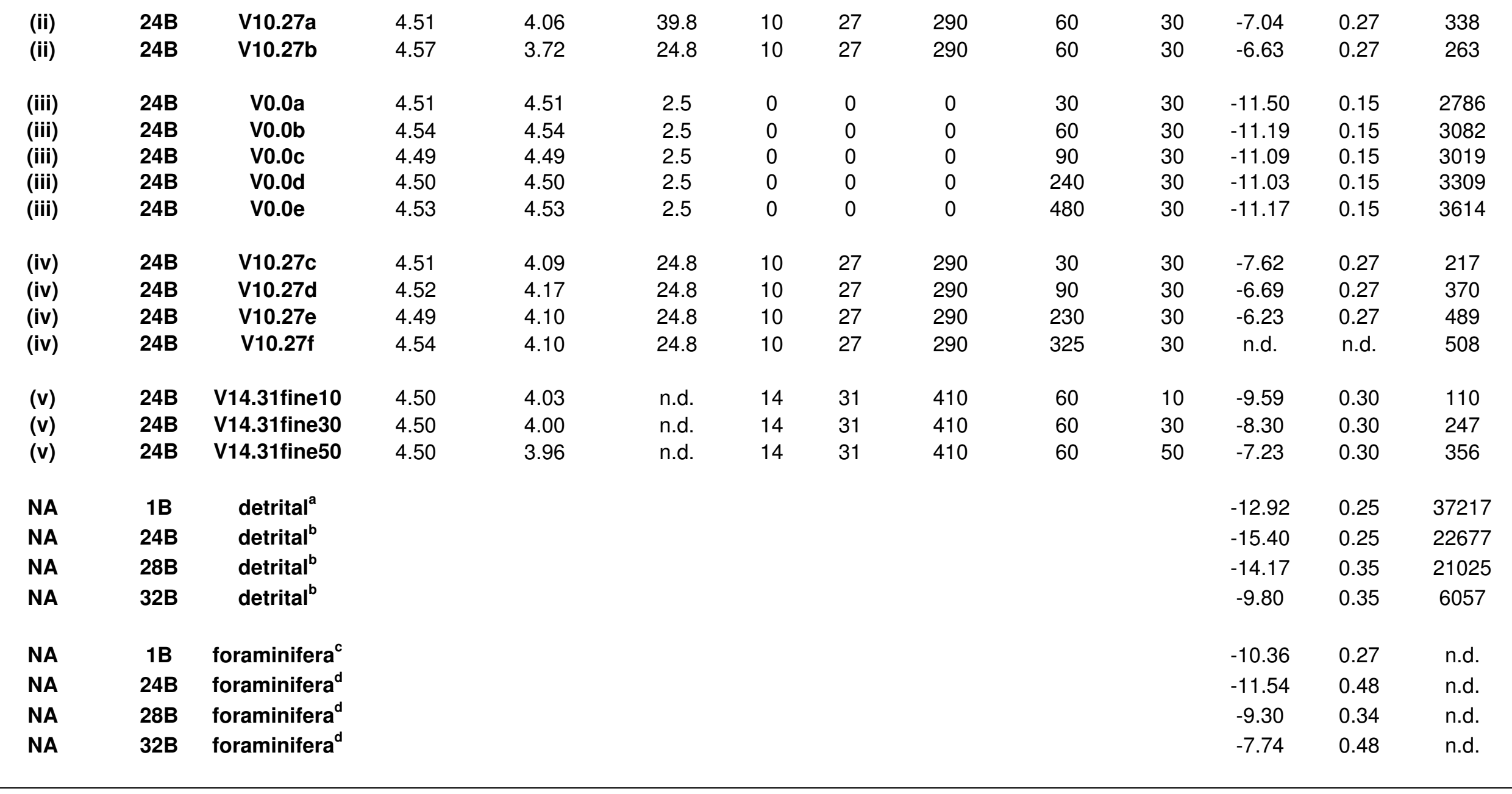

\section{Notes}

Core $=$ WIND core number.

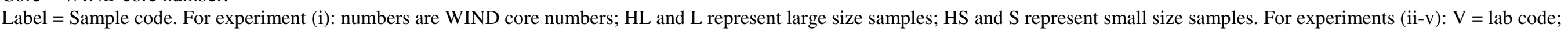

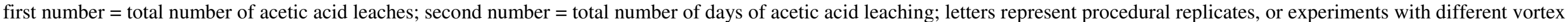

mixing times or $\mathrm{HH}$ leaching times; for experiment (v) fine indicates the fine fraction was used and the final number represents the HH leaching time.

Weight $=$ Wet weight (grams) of sediment leached. The two columns (pre-A and post-A) report weights before and after acetic acid leaching, respectively.

$\mathrm{T}_{\mathrm{vortex}}=$ Time (minutes) of vortex mixing experienced by the sample during sequential leaching process.

$\mathrm{N}_{\mathrm{A}}=$ Number of acetic acid leaches.

$\mathrm{T}_{\mathrm{A}}=$ Total time (days) of acetic acid leaching.

$\mathrm{V}_{\mathrm{A}}=$ Total volume $(\mathrm{mL})$ of acetic acid leaching.

$\mathrm{T}_{\mathrm{HH}}=$ Time (minutes) of $\mathrm{HH}$ leaching. 
$\mathrm{V}_{\mathrm{HH}}=$ Volume $(\mathrm{mL})$ of $\mathrm{HH}$ leaching.

$\varepsilon_{\mathrm{Nd}}=$ Leachate $\varepsilon_{\mathrm{Nd}}$ composition, calculated as $\varepsilon_{\mathrm{Nd}}=\left\{\left({ }^{143} \mathrm{Nd} /{ }^{144} \mathrm{Nd}\right)_{\text {sample }} /\left({ }^{143} \mathrm{Nd} /{ }^{144} \mathrm{Nd}\right)_{\mathrm{CHUR}}-1\right\} * 10,000$.

$2 \sigma=$ Total external error on Nd isotope analysis.

$[\mathrm{Nd}]=\mathrm{Nd}$ concentration in leachate; see Table 4 .

n.d.: not determined.

a: Detrital sediment measured in this study following the procedure described in Wilson et al. (2012).

b: Detrital sediment reported in Wilson et al. (2012).

c: Uncleaned sedimentary planktonic foraminifera measured in this study following the procedure described in Wilson et al. (2012).

$\mathrm{d}$ : Uncleaned sedimentary planktonic foraminifera reported in Wilson et al. (2012). 
Table 4: Elemental concentration data and calculated elemental ratios and REE parameters

\begin{tabular}{|c|c|c|c|c|c|c|c|c|c|c|c|c|c|c|c|c|c|c|c|c|c|c|c|c|c|c|}
\hline Experiment & core & Label & $\begin{array}{l}\text { Wet weight } \\
(g)\end{array}$ & $\begin{array}{c}\mathrm{Fe} \\
\mathrm{ng} / \mathrm{g}\end{array}$ & $\begin{array}{c}\mathrm{Mn} \\
\mathrm{ng} / \mathrm{g}\end{array}$ & $\begin{array}{c}\mathrm{Al} \\
\mathrm{n} / \mathrm{g}\end{array}$ & $\begin{array}{c}\mathrm{Ca} \\
\mathrm{ng} / \mathrm{g} \\
\end{array}$ & $\begin{array}{c}\text { La } \\
\text { ngg/g }\end{array}$ & $\begin{array}{c}\mathrm{Ce} \\
\mathrm{ng} / \mathrm{g}\end{array}$ & $\begin{array}{c}\mathrm{Pr} \\
\mathrm{ng} / \mathrm{g}\end{array}$ & $\begin{array}{c}\mathrm{Nd} \\
\mathrm{Nd} / \mathrm{g}\end{array}$ & $\begin{array}{r}\mathrm{Sm} \\
\mathrm{ng} / \mathrm{g}\end{array}$ & $\begin{array}{c}\text { Eu } \\
\text { nglg }\end{array}$ & $\begin{array}{c}\text { Gd } \\
\text { ang/g }\end{array}$ & $\begin{array}{c}\mathrm{Tb} \\
\mathrm{ng} / \mathrm{g}\end{array}$ & $\begin{array}{c}\begin{array}{c}\mathrm{Dy} \\
\mathrm{ng} / \mathrm{g}\end{array} \\
\end{array}$ & $\begin{array}{c}\text { Ho } \\
\text { ng/g }\end{array}$ & $\begin{array}{c}\begin{array}{c}E r \\
\text { ng/g }\end{array} \\
n\end{array}$ & $\begin{array}{c}\mathrm{Tm} \\
\mathrm{ng} / \mathrm{g}\end{array}$ & $\begin{array}{c}\mathrm{Yb} \\
\mathrm{ng} / \mathrm{g}\end{array}$ & $\begin{array}{c}\mathrm{Lu} \\
\mathrm{Lg} / \mathrm{g}\end{array}$ & AlNd & $\mathrm{Fe} / \mathrm{Mn}$ & HREE/LREE & MREEMREE" & cel/ce" \\
\hline (i) & $1 \mathrm{~B}$ & $1 \mathrm{HL}$ & 5.86 & 33021 & 214768 & 135344 & 34739 & 63.45 & 106.95 & 18.87 & 79.03 & 16.51 & 3.81 & 17.67 & 2.25 & 12.23 & 2.32 & 6.05 & 0.74 & 4.27 & 0.67 & 1713 & 0.15 & 0.77 & 1.71 & 0.71 \\
\hline (i) & $1 \mathrm{~B}$ & $1 \mathrm{~L}$ & 6.48 & 16470 & 195274 & 124753 & 63253 & 67.65 & 108.71 & 19.55 & 83.64 & 17.57 & 4.08 & 18.73 & 2.44 & 13.21 & 2.60 & 6.73 & 0.86 & 5.06 & 0.81 & 1491 & 0.08 & 0.87 & 1.66 & 0.69 \\
\hline (i) & 18 & $1 \mathrm{HS}$ & 2.20 & 943 & 198862 & 127502 & 21946 & 109.73 & 420.67 & 24.44 & 90.95 & 15.39 & 3.18 & 15.00 & 2.06 & 11.62 & 2.35 & 6.62 & 0.92 & 5.71 & 0.82 & 1402 & 0.00 & 0.72 & 1.17 & 1.87 \\
\hline (i) & 18 & $1 \mathrm{~s}$ & 2.24 & 475 & 215551 & 96571 & 18930 & 110.96 & 415.53 & 23.42 & 82.88 & 13.39 & 2.69 & 13.80 & 1.78 & 10.27 & 2.00 & 5.90 & 0.78 & 4.80 & 0.72 & 1165 & 0.00 & 0.64 & 1.13 & 1.88 \\
\hline (i) & 24B & $24 \mathrm{HL}$ & 10.26 & 185882 & 240298 & 129086 & 40720 & 145.51 & 290.86 & 39.12 & 151.57 & 29.06 & 6.28 & 24.09 & 3.42 & 18.96 & 3.51 & 9.70 & 1.37 & 8.39 & 1.25 & 852 & 0.77 & 0.71 & 1.26 & 0.89 \\
\hline (i) & $24 \mathrm{~B}$ & $24 \mathrm{~L}$ & 10.34 & 124938 & 203827 & 74433 & 30909 & 101.64 & 199.20 & 26.01 & 96.54 & 18.01 & 3.92 & 15.26 & 2.13 & 12.03 & 2.26 & 6.37 & 0.89 & 5.62 & 0.83 & 771 & 0.61 & 0.70 & 1.19 & 0.89 \\
\hline (i) & 24B & $24 \mathrm{HS}$ & 3.70 & 413029 & 370651 & 277222 & 95616 & 310.14 & 1113.87 & 89.14 & 321.92 & 59.61 & 12.13 & 50.20 & 7.08 & 39.57 & 7.35 & 21.45 & 3.30 & 19.95 & 2.90 & 861 & 1.11 & 0.77 & 1.16 & 1.54 \\
\hline (i) & 24B & $24 \mathrm{~S}$ & 3.55 & 379403 & 279391 & 242351 & 75251 & 257.10 & 958.40 & 72.46 & 268.83 & 48.49 & 9.83 & 42.77 & 6.10 & 34.20 & 6.42 & 18.75 & 2.96 & 18.50 & 2.61 & 902 & 1.36 & 0.84 & 1.16 & 1.61 \\
\hline (i) & $28 \mathrm{~B}$ & $28 \mathrm{HL}$ & 7.52 & 233160 & 259811 & 234316 & 72860 & 240.56 & 343.34 & 62.94 & 239.66 & 47.77 & 11.18 & 44.83 & 6.49 & 37.51 & 7.25 & 20.65 & 3.04 & 18.53 & 2.81 & 978 & 0.90 & 0.97 & 1.29 & 0.64 \\
\hline (i) & $28 B$ & $28 \mathrm{~L}$ & 7.13 & 241137 & 244147 & 238136 & 49240 & 251.06 & 374.11 & 64.61 & 245.79 & 48.79 & 10.96 & 43.36 & 6.48 & 38.55 & 7.45 & 21.23 & 3.13 & 19.84 & 2.91 & 969 & 0.99 & 0.99 & 1.23 & 0.68 \\
\hline (i) & ${ }^{28 B}$ & $28 \mathrm{HS}$ & 3.57 & 274231 & 249588 & 351434 & 45664 & 235.64 & 767.84 & 60.61 & 215.44 & 37.74 & 7.90 & 31.04 & 4.83 & 29.65 & 5.79 & 17.11 & 2.69 & 17.54 & 2.56 & 1631 & 1.10 & 0.94 & 1.02 & 1.48 \\
\hline (i) & ${ }^{28 B}$ & $28 \mathrm{~S}$ & 3.66 & 298898 & 257063 & 394643 & 51304 & 239.58 & 752.32 & 61.84 & 218.71 & 38.53 & 7.89 & 31.85 & 5.07 & 31.04 & 5.86 & 17.37 & 2.79 & 18.22 & 2.76 & 1804 & 1.16 & 0.97 & 1.03 & 1.42 \\
\hline (i) & 32B & 32 HL & 4.54 & 138860 & 330277 & 935648 & 603215 & 2020.34 & 1067.60 & 463.66 & 2018.34 & 442.81 & 112.69 & 528.47 & 79.10 & 492.95 & 107.80 & 315.04 & 45.41 & 285.57 & 46.12 & 464 & 0.42 & 1.89 & 1.35 & 0.25 \\
\hline (i) & 32B & $32 \mathrm{~L}$ & 4.58 & 105484 & 297649 & 815194 & 662264 & 1972.99 & 1029.95 & 465.76 & 2062.92 & 456.65 & 117.33 & 567.18 & 82.02 & 513.98 & 113.84 & 333.83 & 47.91 & 299.72 & 49.55 & 395 & 0.35 & 1.99 & 1.36 & 0.25 \\
\hline (i) & $32 \mathrm{~B}$ & $32 \mathrm{HS}$ & 1.77 & 302848 & 308810 & 2203257 & 14359 & 313.58 & 778.42 & 50.28 & 153.49 & 22.81 & 4.91 & 20.75 & 3.68 & 25.32 & 5.72 & 20.30 & 3.90 & 27.82 & 3.99 & 14354 & 0.98 & 1.52 & 0.63 & 1.41 \\
\hline (i) & $32 \mathrm{~B}$ & $32 \mathrm{~s}$ & 1.81 & 208712 & 272866 & 1540467 & 15149 & 264.96 & 711.96 & 44.15 & 133.33 & 21.08 & 4.24 & 18.38 & 3.22 & 22.17 & 4.94 & 17.20 & 3.31 & 23.18 & 3.40 & 11553 & 0.76 & 1.49 & 0.65 & 1.50 \\
\hline (ii) & 24B & v1.1 & 4.86 & 448629 & 526700 & 167113 & 20864477 & 4636.82 & 6081.75 & 1328.17 & 5628.14 & 1255.17 & 298.76 & 1309.94 & 183.53 & 1019.02 & 198.61 & 531.68 & 68.77 & 406.65 & 62.73 & 30 & 0.85 & 1.02 & 1.67 & 0.56 \\
\hline (ii) & 24B & v2.2 & 4.66 & 561865 & 724874 & 563866 & 2330807 & 1481.09 & 2307.09 & 440.24 & 1874.39 & 411.44 & 99.51 & 425.08 & 59.03 & 329.16 & 63.16 & 170.79 & 23.19 & 142.30 & 22.24 & 301 & 0.78 & 1.07 & 1.59 & 0.65 \\
\hline (ii) & $24 \mathrm{~B}$ & V2.7 & 4.34 & 511317 & 669572 & 333185 & 2024162 & 1500.72 & 2241.84 & 430.89 & 1782.07 & 377.32 & $\begin{array}{l}90.68 \\
96\end{array}$ & 373.90 & 53.25 & 291.31 & 56.01 & 152.76 & 20.43 & 123.96 & 19.42 & 187 & 0.76 & 0.96 & 1.53 & 0.64 \\
\hline (ii) & 24B & $\begin{array}{l}\text { val. } \\
\text { v3.3 }\end{array}$ & $\begin{array}{l}4.34 \\
4.57\end{array}$ & 412516 & 720755 & 2380023 & 791428 & 682.31 & $\begin{array}{l}2.47 .04 \\
1170.83\end{array}$ & $\begin{array}{l}40.05 \\
161.63\end{array}$ & 630.88 & $\begin{array}{l}1,32.02 \\
122.01\end{array}$ & 27.95 & $\begin{array}{l}114.90 \\
11403\end{array}$ & $\begin{array}{l}14.74 \\
14.74\end{array}$ & 77.46 & $\begin{array}{l}50.01 \\
14.57\end{array}$ & $\begin{array}{l}39.26 \\
39.26\end{array}$ & $\begin{array}{l}5.05 \\
5.05\end{array}$ & 31.25 & $\begin{array}{l}31.48 \\
4.88\end{array}$ & 377 & 0.57 & 0.56 & $\begin{array}{l}1.53 \\
1.36\end{array}$ & 0.04 \\
\hline (ii) & 24B & V4.7 & 4.57 & 317367 & 716992 & 179850 & 248058 & 516.76 & 851.03 & 85.02 & 294.79 & 48.01 & 10.91 & 44.72 & 5.83 & 32.51 & 6.28 & 17.47 & 2.22 & 14.00 & 2.16 & 610 & 0.44 & 0.47 & 1.03 & 0.92 \\
\hline (ii) & $24 \mathrm{~B}$ & v5.13a & 4.10 & 455822 & 428688 & 292392 & 113820 & 329.30 & 936.11 & 90.56 & 345.00 & 63.85 & 13.90 & 53.48 & 7.84 & 44.69 & 8.49 & 23.77 & 3.58 & 21.27 & 3.29 & 848 & 1.06 & 0.80 & 1.19 & 1.25 \\
\hline (ii) & 24B & v5.13b & 4.09 & 429045 & 397775 & 286021 & 70566 & 315.89 & 920.63 & 87.36 & 335.98 & 62.22 & 13.14 & 53.46 & 7.76 & 43.40 & 7.88 & 22.19 & 3.27 & 20.70 & 2.96 & 851 & 1.08 & 0.77 & 1.24 & 1.27 \\
\hline (ii) & $24 B$ & v6.14a & 4.04 & 386117 & 366479 & 251332 & 64660 & 293.38 & 821.45 & 75.78 & 278.76 & 51.31 & 10.87 & 42.08 & 6.16 & 34.52 & 6.62 & 18.69 & 2.77 & 17.05 & 2.55 & 902 & 1.05 & 0.74 & 1.14 & 1.27 \\
\hline (ii) & 24B & v6.14b & 4.01 & 480745 & 455168 & 321017 & 87329 & 368.26 & 1021.29 & 98.45 & 372.30 & 71.31 & 15.09 & 59.10 & 8.84 & 47.55 & 9.03 & 25.02 & 3.62 & 22.78 & 3.39 & 862 & 1.06 & 0.76 & 1.23 & 1.23 \\
\hline (ii) & 24B & V7.16a & 4.08 & 434835 & 405214 & 279409 & 83493 & 317.24 & 976.12 & 86.76 & 320.41 & 59.49 & 12.68 & 49.45 & 7.03 & 40.87 & 7.62 & 21.31 & 3.23 & 20.19 & 2.83 & 872 & 1.07 & 0.76 & 1.17 & 1.35 \\
\hline (ii) & $\begin{aligned} 24 B \\
24 B\end{aligned}$ & $\begin{array}{l}\text { V7.1.16b } \\
\text { y8 }\end{array}$ & $\begin{array}{l}4.08 \\
40.3\end{array}$ & $\begin{array}{l}4122297 \\
404248\end{array}$ & $\begin{array}{r}394066 \\
338077\end{array}$ & $\begin{array}{l}258714 \\
2553414\end{array}$ & $\begin{array}{l}67086 \\
89466\end{array}$ & 311.78 & $\begin{array}{l}908.87 \\
959324\end{array}$ & $\begin{array}{l}80.90 \\
77.52\end{array}$ & 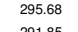 & $\begin{array}{l}54.79 \\
5.25\end{array}$ & $\begin{array}{l}10.71 \\
\end{array}$ & 45.71 & 6.32 & 36.20 & 6.54 & 18.75 & 2.80 & $\begin{array}{l}17.46 \\
1707\end{array}$ & $\begin{array}{l}2.57 \\
.257\end{array}$ & 875 & 1.05 & 0.71 & 1.15 & 1.32 \\
\hline (ii) & $\begin{array}{l}{ }^{24 B} \\
{ }_{2}^{24 B}\end{array}$ & $\begin{array}{l}\text { v8.20a } \\
\text { v8.20b }\end{array}$ & $\begin{array}{l}4.03 \\
403\end{array}$ & $\begin{array}{l}{ }_{426478} \\
4446838\end{array}$ & $\begin{array}{l}380716 \\
3845416\end{array}$ & $\begin{array}{l}{ }^{2543414} \\
2660447\end{array}$ & $\begin{array}{l}89466 \\
59520\end{array}$ & $\begin{array}{l}305.15 \\
25771\end{array}$ & $\begin{array}{l}953.24 \\
95909\end{array}$ & $\begin{array}{l}79.52 \\
68.77\end{array}$ & $\begin{aligned} & 291.85 \\
& 22555\end{aligned}$ & $\begin{array}{l}52.35 \\
4574\end{array}$ & $\begin{array}{l}10.77 \\
9910\end{array}$ & $\begin{array}{l}45.61 \\
3838\end{array}$ & $\begin{array}{l}6.52 \\
5\end{array}$ & 37.10 & 6.78 & 19.10 & 2.83 & 17.67 & $\begin{array}{l}2.57 \\
2.1\end{array}$ & 871 & 1.12 & 0.73 & 1.18 & 1.41 \\
\hline $\begin{array}{l}\text { (ii) } \\
\text { (ii) }\end{array}$ & $\begin{array}{l}24 B \\
248 \\
248\end{array}$ & $\begin{array}{l}\text { v8.20b } \\
\text { v.9.22a }\end{array}$ & $\begin{array}{l}\begin{array}{l}4.03 \\
4.05\end{array} \\
4\end{array}$ & $\begin{array}{l}\begin{array}{l}4466838 \\
446772\end{array} \\
4\end{array}$ & $\begin{array}{l}3845411 \\
383307\end{array}$ & $\begin{array}{l}266477 \\
244800\end{array}$ & $\begin{array}{l}59520 \\
70013\end{array}$ & $\begin{array}{l}2527.71 \\
278.49\end{array}$ & $\begin{array}{l}959.920 \\
1018.33\end{array}$ & $\begin{array}{l}68.77 \\
74.89\end{array}$ & 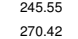 & $\begin{array}{l}45.74 \\
50.86\end{array}$ & $\begin{array}{l}9.10 \\
10.05\end{array}$ & $\begin{array}{l}38.38 \\
44.50\end{array}$ & $\begin{array}{l}5.39 \\
6.14\end{array}$ & $\begin{array}{l}3.1 .33 \\
33.36\end{array}$ & $\begin{array}{l}5.89 \\
6.08\end{array}$ & $\begin{array}{l}16.70 \\
17.47\end{array}$ & $\begin{array}{l}2.36 \\
2.67\end{array}$ & $\begin{array}{l}14.93 \\
16.08\end{array}$ & $\begin{array}{l}2.19 \\
2.34\end{array}$ & $\begin{array}{l}1061 \\
916\end{array}$ & $\begin{array}{l}1.17 \\
1.17\end{array}$ & $\begin{array}{l}0.72 \\
0.72\end{array}$ & $\begin{array}{l}1.17 \\
1.17\end{array}$ & $\begin{array}{l}1.66 \\
1.62\end{array}$ \\
\hline (ii) & $24 \mathrm{~B}$ & v9.22b & 3.88 & 450939 & 391065 & 264529 & 82027 & 301.64 & 1068.00 & 81.88 & 303.02 & $\begin{array}{l}50.00 \\
56.39\end{array}$ & $\begin{array}{l}11.23 \\
11.23\end{array}$ & 46.25 & $\begin{array}{l}6.78 \\
6.78\end{array}$ & $\begin{array}{l}30.50 \\
37.40\end{array}$ & $\begin{array}{l}6.90 \\
6.92\end{array}$ & $\begin{array}{l}17.47 \\
19.33\end{array}$ & $\begin{array}{l}2.67 \\
3.00\end{array}$ & $\begin{array}{l}\begin{array}{l}66.08 \\
18.29\end{array} \\
1\end{array}$ & $\begin{array}{l}2.34 \\
2.68\end{array}$ & $\begin{array}{l}916 \\
873\end{array}$ & $\begin{array}{l}1.17 \\
1.15\end{array}$ & $\begin{array}{l}0.72 \\
0.75\end{array}$ & $\begin{array}{l}1.17 \\
1.17\end{array}$ & $\begin{array}{l}1.62 \\
1.56\end{array}$ \\
\hline (ii) & 24B & v10.27a & 4.06 & 541979 & 449421 & 320081 & 159735 & 340.44 & 1383.64 & 92.00 & 337.64 & 62.88 & 12.58 & 54.46 & 7.51 & 42.77 & $\begin{array}{l}.032 \\
7.82\end{array}$ & $\begin{array}{l}\begin{array}{r}19.33 \\
21.93\end{array} \\
2.93\end{array}$ & $\begin{array}{l}3.00 \\
3.23\end{array}$ & $\begin{array}{l}18.29 \\
19.69\end{array}$ & $\begin{array}{l}2.288 \\
2.78\end{array}$ & $\begin{array}{l}873 \\
948\end{array}$ & $\begin{array}{l}7.15 \\
1.21\end{array}$ & $\begin{array}{l}0.15 \\
0.71\end{array}$ & $\begin{array}{l}1.17 \\
1.22\end{array}$ & $\begin{array}{l}1.56 \\
1.80\end{array}$ \\
\hline (ii) & $24 \mathrm{~B}$ & v10.27b & 3.72 & 404150 & 322712 & 241519 & 71512 & 261.23 & 1089.24 & 71.44 & 262.90 & 49.97 & 9.82 & 40.80 & 5.76 & 33.41 & 6.00 & 17.33 & $\begin{array}{l}\text {.23 } \\
2.42\end{array}$ & $\begin{array}{l}99.69 \\
15.39\end{array}$ & $\begin{array}{l}2.18 \\
2.20\end{array}$ & $\begin{array}{l}940 \\
919\end{array}$ & 1.25 & 0.71 & $\begin{array}{l}1.22 \\
1.22\end{array}$ & $\begin{array}{l}1.00 \\
1.83\end{array}$ \\
\hline (iii) & 248 & vo.oa & 4.51 & 156523 & 403206 & 27408 & 37484653 & 2616.25 & 31111.10 & 664.90 & 2786.00 & 619.10 & 145.94 & 657.49 & 87.22 & 493.78 & 94.37 & 245.55 & 29.93 & 173.41 & 26.60 & 10 & 0.39 & 0.85 & 1.72 & 0.54 \\
\hline (iii) & $24 B$ & vo.ob & 4.54 & 200237 & 407469 & 30500 & 39428624 & 2873.96 & 4030.17 & 733.75 & 3081.74 & 675.22 & 160.22 & 727.60 & 96.26 & 551.50 & 106.46 & 285.06 & 34.87 & 205.38 & 32.26 & & 0.49 & 0.91 & 1.67 & 0.64 \\
\hline (iii) & 24B & vo.oc & 4.49 & 197060 & 396035 & 30307 & 36848211 & 2877.29 & 4901.76 & 722.53 & 3018.70 & 657.18 & 157.69 & 718.80 & 93.31 & 534.56 & 103.86 & 275.78 & 33.38 & 197.63 & 30.77 & 10 & 0.50 & 0.88 & 1.68 & 0.78 \\
\hline (iii) & $24 \mathrm{~B}$ & vo.od & 4.50 & 278836 & 398944 & 57329 & 37532952 & 3102.08 & 6073.19 & 787.13 & 3308.74 & 728.48 & 173.29 & 788.09 & 104.35 & 607.34 & 116.51 & 309.91 & 38.66 & 232.96 & 35.91 & 17 & 0.70 & 0.95 & 1.66 & 0.90 \\
\hline $\begin{array}{l}\text { (iii) } \\
\text { (iil) }\end{array}$ & 24B & vo.oe & 4.53 & 374992 & 4049977 & 83489 & 381548000 & 3364.16 & 7690.58 & 864.40 & 3613.51 & 775.73 & 188.30 & 841.37 & $\begin{array}{l}112.82 \\
112.82\end{array}$ & 666.90 & 127.65 & 345.03 & 44.08 & $\begin{array}{l}265.04 \\
265\end{array}$ & 41.02 & 23 & 0.93 & 0.99 & 1.61 & 1.04 \\
\hline (iv) & 24B & v10.27c & 4.09 & 358826 & 340985 & 213738 & 64842 & 218.63 & 673.72 & 58.40 & 217.31 & 40.17 & 8.22 & 30.86 & 4.63 & 27.36 & 5.02 & 14.04 & 2.09 & 13.52 & 1.88 & 984 & 1.05 & 0.74 & 1.13 & 1.37 \\
\hline (iv) & $24 B$ & V10.27d & 4.17 & 548121 & 437621 & 312211 & 102599 & 358.12 & 1348.35 & 98.00 & 370.46 & 68.47 & 13.29 & 58.66 & 8.20 & 46.69 & 8.42 & 24.07 & 3.50 & 22.10 & 3.16 & 843 & 1.25 & 0.74 & 1.22 & 1.65 \\
\hline (iv) & $24 \mathrm{~B}$ & V10.27e & 4.10 & 627910 & 416060 & 354718 & 134596 & 457.83 & 2246.43 & 130.80 & 488.84 & 92.23 & 18.50 & 78.92 & 10.85 & 61.95 & 11.43 & 32.67 & 4.57 & 28.63 & 4.11 & 726 & 1.51 & 0.73 & 1.24 & 2.11 \\
\hline (iv) & $24 \mathrm{~B}$ & $\mathrm{~V} 10.27 \mathrm{f}$ & 4.10 & 541620 & 420706 & 346280 & 144852 & 494.58 & 2338.21 & & 507.76 & 92.89 & 18.34 & 88.15 & 11.31 & 63.55 & 11.80 & 33.27 & 4.80 & 29.71 & 4.35 & 682 & 1.29 & 0.73 & 1.26 & 2.09 \\
\hline (v) & 24B & V14.31tine10 & 4.03 & 366694 & 336119 & 94228 & 75032 & 109.11 & 479.88 & 30.73 & 110. & 19.48 & 4.56 & 18.01 & 2.29 & 12.42 & 2.30 & 6.72 & 1.00 & 6.40 & 0.89 & 854 & 1.09 & 0.69 & 1.17 & 1.90 \\
\hline (v) & 24B & V14.31tine30 & 4.00 & 369310 & 350063 & 186209 & 79972 & 249.08 & 1136.30 & 67.73 & 246.82 & 43.90 & 8.94 & 41.51 & 4.90 & 28.32 & 5.22 & 14.94 & 2.29 & 14.24 & 2.08 & 754 & 1.05 & 0.70 & 1.17 & 2.01 \\
\hline (v) & ${ }_{24 B}$ & V14.31 thine50 & 3.96 & 492511 & 359927 & 292294 & 94938 & 321.41 & $\begin{array}{l}1582.70 \\
\end{array}$ & 94.12 & 355.55 & 66.88 & $\begin{array}{l}13.29 \\
\end{array}$ & 59.04 & 7.79 & 44.59 & 8.36 & 23.86 & 3.63 & 22.76 & 3.20 & 822 & 1.37 & 0.80 & 1.21 & 2.08 \\
\hline NA & 18 & detrital & 0.0294 & 751521855 & 583290 & 148250029 & 4130125 & 45773.85 & 1068 & 10292.91 & 37217.34 & 6564.33 & 1363.23 & 5566.43 & 866.83 & 5307.55 & 1046.72 & 3110 & 489 & 3222.66 & 476.92 & 3983 & 128.84 & 0.97 & 1.01 & 1.14 \\
\hline NA & $24 \mathrm{~B}$ & detrital & 0.0320 & 43140243 & 351227 & 85824654 & 6607939 & 30764.70 & 64077.17 & 6365.10 & 22676.58 & 3986.31 & 919.96 & 3165.89 & 474.41 & 2607.50 & 500.87 & 1431.01 & 212.04 & 1396.13 & 199.28 & 3785 & 122.83 & 0.65 & 1.02 & 1.05 \\
\hline NA & ${ }_{28 \mathrm{~B}}$ & detritial & 0.0290 & 41884089 & 293465 & 83893463 & 5094058 & 29275.84 & 61828.41 & 5959.25 & 21024.61 & 3715.94 & 856.93 & 2949.39 & 459.25 & 2591.66 & 493.91 & 1451.25 & 221.85 & 1445.03 & 206.61 & 3990 & 142.72 & 0.72 & 1.00 & 1.08 \\
\hline NA & $32 \mathrm{~B}$ & detrital & 0.0309 & 1327874 & 86300 & 23426170 & 1356601 & 8616.66 & 24732.27 & 1743.25 & 6057.13 & 1082.07 & 275.98 & 884.29 & 159.12 & 1111.24 & 233.03 & 780.08 & 144.96 & 1058.17 & 159.92 & 3868 & 153.87 & 1.79 & 0.76 & 1.47 \\
\hline
\end{tabular}

\section{Notes}

Core $=$ WIND core number

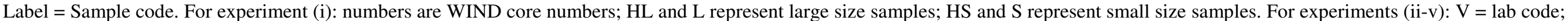

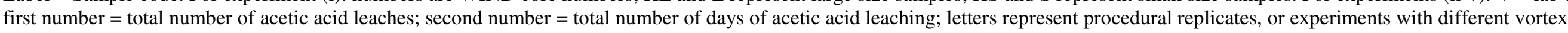
mixing times or $\mathrm{HH}$ leaching times; for experiment (v) fine indicates the fine fraction was used and the final number represents the HH leaching time. 
Wet weight $=$ Wet weight (grams) of sediment leached (after acetic acid leaching/decarbonation). 